\title{
Article \\ Chloramphenicol Loaded Sponges Based on PVA/Nanocellulose Nanocomposites for Topical Wound Delivery
}

\author{
Evangelia D. Balla ${ }^{1} \mathbb{D}$, Nikolaos D. Bikiaris ${ }^{1}$, Stavroula G. Nanaki ${ }^{1}$, Chrysanthi Papoulia ${ }^{2} \mathbb{D}$, \\ Konstantinos Chrissafis ${ }^{2}$, Panagiotis A. Klonos ${ }^{1,3}{ }^{-}$, Apostolos Kyritsis ${ }^{3}$, Margaritis Kostoglou 4 , \\ Alexandra Zamboulis $1, * \mathbb{D}$ and George Z. Papageorgiou ${ }^{5, *(\mathbb{B}}$
}

Citation: Balla, E.D.; Bikiaris, N.D.; Nanaki, S.G.; Papoulia, C.; Chrissafis, K.; Klonos, P.A.; Kyritsis, A.; Kostoglou, M.; Zamboulis, A.; Papageorgiou, G.Z. Chloramphenicol Loaded Sponges Based on PVA/Nanocellulose Nanocomposites for Topical Wound Delivery. J. Compos. Sci. 2021, 5, 208. https://doi.org/10.3390/jcs5080208

Academic Editor:

Francesco Tornabene

Received: 11 July 2021

Accepted: 3 August 2021

Published: 6 August 2021

Publisher's Note: MDPI stays neutral with regard to jurisdictional claims in published maps and institutional affiliations.

Copyright: () 2021 by the authors Licensee MDPI, Basel, Switzerland. This article is an open access article distributed under the terms and conditions of the Creative Commons Attribution (CC BY) license (https:// creativecommons.org/licenses/by/ $4.0 /$ )
1 Laboratory of Polymer Chemistry and Technology, Department of Chemistry, Aristotle University of Thessaloniki, 54124 Thessaloniki, Greece; evangeldm@gmail.com (E.D.B.); nbikiaris@gmail.com (N.D.B.); sgnanaki@chem.auth.gr (S.G.N.); pklonos@central.ntua.gr (P.A.K.)

2 Laboratory of Advanced Materials \& Devices, Department of Physics, Aristotle University of Thessaloniki, 54124 Thessaloniki, Greece; cpapouli@physics.auth.gr (C.P.); hrisafis@physics.auth.gr (K.C.)

3 Department of Physics, Zografou Campus, National Technical University of Athens, 15780 Athens, Greece; akyrits@central.ntua.gr

4 Laboratory of Chemical and Environmental Technology, Department of Chemistry, Aristotle University of Thessaloniki, 54124 Thessaloniki, Greece; kostoglu@chem.auth.gr

5 Institute of Materials Science and Computing, University Research Center of Ioannina (URCI), 45110 Ioannina, Greece

* Correspondence: azampouli@chem.auth.gr (A.Z.); gzpap@uoi.gr (G.Z.P.)

Abstract: In the present study, polymer sponges based on poly(vinyl alcohol) (PVA) were prepared for the topical wound administration of chloramphenicol (CHL), an antibiotic widely used to treat bacterial infections. Nanocellulose fibrils (CNF) were homogenously dispersed in PVA sponges in three different ratios $(2.5,5$, and $10 \mathrm{wt} \%)$ to improve the mechanical properties of neat PVA sponges. Infrared spectroscopy showed hydrogen bond formation between CNF and PVA, while scanning electron microscopy photos verified the successful dispersion of CNF to PVA sponges. The addition of CNF successfully enhanced the mechanical properties of PVA sponges, exhibiting higher compressive strength as the content of CNF increased. The PVA sponge containing $10 \mathrm{wt} \% \mathrm{CNF}$, due to its higher compression strength, was further studied as a matrix for CHL delivery in 10, 20, and $30 \mathrm{wt} \%$ concentration of the drug. X-ray diffraction showed that CHL was encapsulated in an amorphous state in the 10 and $20 \mathrm{wt} \%$ samples, while some crystallinity was observed in the $30 \mathrm{wt} \%$ ratio. In vitro dissolution studies showed enhanced CHL solubility after its incorporation in PVA/10 wt \% CNF sponges. Release profiles showed a controlled release lasting three days for the sample containing $10 \mathrm{wt} \% \mathrm{CHL}$ and 1.5 days for the other two samples. According to modelling, the release is driven by a pseudo-Fickian diffusion.

Keywords: poly(vinyl alcohol) sponges; cellulose nanofibrils; chloramphenicol; topical wound delivery; sustained release

\section{Introduction}

A wound refers to any tear, cut, or burn created in the skin, i.e., a disruption of the continuous structure of skin, caused by trauma or burn, or as a result of a medical condition. The successful and effective healing of wound includes various factors, and the role of a wound dressing is to create a favorable environment to support healing with an aesthetically satisfactory result $[1,2]$. More specifically, an ideal dressing should be non-toxic and non-allergenic, biocompatible, allow gas exchange, and protect the wound from any external mechanical stress. It has been demonstrated that a wet interface between the wound and the dressing can accelerate the healing process; so, in addition, the 
wound dressing should provide and maintain a wet environment on the surface of the damaged skin. Infections delay the healing process and smart wound dressings have been developed for the controlled release of antibacterial and antimicrobial drugs to inhibit their development [3-6].

Polymeric nanocarriers present numerous benefits in topical drug delivery, such as high stability both in vivo and in vitro, good biocompatibility, and multifunctionality. In general, the encapsulation of drugs in polymeric materials allows (a) an enhanced dissolution rate of insoluble or hydrophobic drugs, (b) a sustained and controlled drug release, as well as (c) a targeted delivery and immune system evasion through appropriate surface functionalization, thus, overall, enhancing the therapeutic efficacy while limiting side-effects [7-9]. Natural and synthetic polymers, such as chitosan, poly(lactic acid) (PLA), poly(lactic-co-glycolic acid) (PLGA), and poly(vinyl alcohol) (PVA), have been studied for the delivery of different types of drugs and biologically active molecules for wound healing applications $[2,7,10-13]$.

PVA is a biocompatible synthetic polymer that has been used extensively for pharmaceutical applications. Its properties depend on its molecular weight and hydrolysis degree, which, in turn, affect the amount of pendant hydroxyl groups [14-18]. PVA foams are particularly appropriate for wound healing applications, as they can absorb significant amounts of exudate due to their porous and hydrophilic character; however, they tend to lack in terms of mechanical strength $[3,19]$. This drawback can be circumvented with the addition of reinforcing agents and the formation of composites. In the present work, cellulose nanofibrils (CNF) were chosen for this purpose. Cellulose, a linear homopolysaccharide of $\beta-1-4$ glucopyranose units, constitutes the main structural unit of wood and of the primary cell wall of green plants, and is the most abundant organic polymer in the environment [20-22]. Cellulose and nanocellulose, i.e., extracts of cellulose with defined nanoscale dimensions, have outstanding properties: good mechanical behavior, low density, biodegradability, and availability from renewable resources [20]. Additionally, nanocellulose is an ideal material for wound dressing due to its excellent ability to absorb exudates during the dressing process and its good compaction property [22,23]. Nanocellulose has been applied in clinical practice for dressing of diabetic ulcer, burn wounds and deep wounds [24,25].

Most studies regarding PVA use chemical crosslinking agents in order to improve its mechanical properties. For example, Liu et al. prepared PVA hydrogels with cellulose nanocrystals (CNC) as reinforcing agents and quaternary ammonium xylan as a cationic molecule to form strong electrostatic interactions with the CNC [26]. The resulting nanocomposite hydrogels, containing up to $20 \mathrm{wt} \%$ PVA, showed enhanced mechanical properties (maximum compressive strength $1.56 \mathrm{MPa}$, elongation at break $771 \%$ ). Lu et al. described a double crosslinking system, affording PVA composite hydrogels with a chemical crosslinked network and ionically crosslinked domains, that showed enhanced mechanical strength and toughness [27]. Novel studies using only a physical crosslinking of PVA with different types of cellulose take advantage of the numerous hydroxyl groups present in PVA chemical structure. Forti et al. used PVA of different molecular weights and degrees of hydrolysis and found that a higher hydrolysis level of PVA resulted in CNF/PVA films exhibiting increased mechanical properties [28]. Finally, Song et al. also reported physically crosslinked PVA and bacterial cellulose hydrogels, where the incorporation of silver nanoparticles imparted antibacterial properties [29]. Resulting formulations showed high porosity, enhanced mechanical properties, and increased water absorption, ensuring the adherence to wound surface.

Stability plays a key role in the preparation of sponges used as wound healing materials. In the present study, cellulose was used in nanofibrils, aiming to reinforce PVA foams. Cellulose nanofibrils (CNFs) are micrometer-long entangled fibrils that comprise both amorphous and crystalline cellulose domains [21] and are used as a reinforcing phase in various polymer matrices $[30,31]$. CNFs were added in three different ratios in PVA and the properties of the obtained materials were further studied. The PVA/CNF sponges were also 
evaluated after the preparation of chloramphenicol (CHL) loaded wound dressings. CHL (Scheme 1) is a broad-spectrum antibiotic used extensively in topical treatment. The main drawback of chloramphenicol is its very low aqueous solubility, which limits its bioavailability and, thus, its therapeutic efficiency [32,33]. Rihawy et al. studied the chemical crosslinking of PVA reinforced with carboxymethylcellulose (CMC) with 2-hydroxyethyl acrylate (HEA) using CHL as an antibacterial drug [34]. It was found that the CHL releasing process was enhanced by reducing HEA amount. The present study describes a significant improvement in CHL dissolution rate, achieved with the CHL-loaded sponges.<smiles>CCC(C)C(C)O</smiles>

PVA

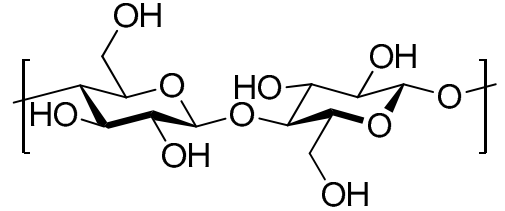

CNF<smiles>O=C(N[C@@H](CO)[C@H](O)c1ccc([N+](=O)[O-])cc1)C(Cl)Cl</smiles>

CHL

Scheme 1. Structures of poly(vinyl alcohol) (PVA), cellulose (CNF), and chloramphenicol (CHL).

\section{Materials and Methods}

\subsection{Materials}

Poly(vinyl alcohol) (PVA) (molecular weight: 13.000-23.000, degree of hydrolysis: 87-89\%) was purchased from Sigma-Aldrich (Sigma-Aldrich Chemie GmbH, Taufkirchen, Germany). Cellulose nanofibrils (CNF) were purchased from the University of Maine (Orono, Maine, USA). Chloramphenicol was kindly donated by Pharmathen S.A. (Athens, Greece). All other reagents and solvents used were of analytical grade.

\subsection{Preparation of $P V A / C N F$ Sponges}

For the preparation of PVA/CNF sponges, a $3 \mathrm{wt} \%$ aqueous solution of PVA was prepared. Appropriate amounts of CNF were dispersed in $20 \mathrm{~mL}$ distilled water by probe sonication (1 cycle, amplitude 100\%) (Ultrasonic Processor UP100H, Hielscher, made in Germany) for $5 \mathrm{~min}$. CNF resulting suspensions were added to $20 \mathrm{~mL}$ of PVA solution in order to obtain a final CNF content of 2.5, 5, and $10 \mathrm{wt} \%$ in the sponges, and homogenization was conducted under sonication for $5 \mathrm{~min}$. The resulting dispersions were freeze-dried under reduced pressure at $-60^{\circ} \mathrm{C}$ (CoolSafe ${ }^{\mathrm{TM}}$, Scanvac, Lynge Denmark) and sponge-like foams were obtained. All formulations were kept under vacuum till further use.

\subsection{Preparation of $\mathrm{CHL}$ Loaded Sponges}

A PVA sponge with CNF $10 \mathrm{wt} \%$ was selected as a matrix for the chloramphenicol (CHL) delivery system. The proper amount of CHL was dissolved in absolute ethanol and added in PVA/CNF $10 \mathrm{wt} \%$ dispersions, prepared as previously described (Section 2.2). The resulting $\mathrm{CHL}$ loaded dispersions were homogenized by sonication and freeze-dried (CoolSafe ${ }^{\mathrm{TM}}$, Scanvac, Lynge, Denmark) under reduced pressure at $-60^{\circ} \mathrm{C}$, and porous sponges were finally obtained. Three different concentrations of CHL-10, 20, and $30 \mathrm{wt} \%$-were prepared. All formulations were kept under vacuum until further use.

In order to determine the drug loading, $10 \mathrm{mg}$ of the prepared sponges were immersed in $10 \mathrm{~mL}$ of dichloromethane for $24 \mathrm{~h}$. The supernatant was filtered and analyzed by HPLC to calculate the amount of drug contained in the sponge (Drug Loading $(\%)=([$ weight of the drug in sponge]/[weight of sponge] $\times 100$ ). Entrapment efficiency was calculated by comparing the real amount of drug contained in the sponge (measured by HPLC) against the theoretical amount of drug (based on the weight of CHL that was used during drug loading). 


\subsection{Characterization of the Prepared Sponges}

2.4.1. Fourier-Transformed Infrared Spectroscopy (FTIR)

The chemical structure of the synthesized materials was determined with FTIR spectroscopy. FTIR spectra of the samples were recorded with an FTIR spectrometer (model FTIR-2000, Perkin Elmer, Waltham, MA, USA) using KBr discs (thickness of $500 \mu \mathrm{m}$ ) in the range from 4000 to $400 \mathrm{~cm}^{-1}$ and at a resolution of $2 \mathrm{~cm}^{-1}$ (total of 64 co-added scans). All spectra were baseline corrected.

\subsubsection{Wide Angle $X$-ray Scattering}

$X$-ray powder diffraction (XRD) patterns were recorded using an XRD-diffractometer (Rigaku-Miniflex II, Chalgrove, Oxford, UK) with a $\mathrm{CuK} \alpha$ radiation for crystalline phase identification $(\lambda=0.15405 \mathrm{~nm}$ for $\mathrm{CuK} \alpha)$. The samples were scanned from 5 to $50^{\circ}$.

\subsubsection{Microscopy}

The PVA/CNF sponges were initially observed with a ZEISS (Oberkochen, Germany) SteREO Discovery V20 microscope, and pictures were taken with a Jenoptik (Jena, Germany) ProgRes GRYPHAX Altair camera and a Gryphax image capturing software. Further insight into the structure of the materials was obtained by scanning electron microscopy (SEM). SEM images were obtained with an electron microscope (JEOL 2011). The freezedried samples were covered with a carbon coating in order to provide a good conductivity for the electron beam. Operating conditions were the following: accelerating voltage $20 \mathrm{kV}$, probe current $45 \mathrm{nA}$, and counting time $60 \mathrm{~s}$.

\subsubsection{Mechanical Stress Properties}

Compression tests ( $n=5$ per condition) were performed using Instron 3344 (Instron Int. Ltd., Norwood, MA, USA) single column universal testing system at room temperature, according to ASTM D-695. Cylinders of $1.0 \mathrm{~cm}$ in diameter and $1.2 \mathrm{~cm}$ in thickness were placed between the two hardened-steel compression platens, and compression tests were conducted at a crosshead speed of $5.0 \mathrm{~mm} / \mathrm{min}$. The compressive strength and strain were calculated from the recorded stress-strain lines.

\subsubsection{Thermogravimetric Analysis}

Thermogravimetric analysis (TGA) was carried out in a Setsys 16/18 TG-DTA (Setaram Instrumentation, Lyon, France) instrument. Samples $(10 \pm 0.5 \mathrm{mg})$ were placed in alumina crucibles. An empty alumina pan was used as a reference. The samples were heated from ambient temperature to $600{ }^{\circ} \mathrm{C}$ in a $50 \mathrm{~mL} / \mathrm{min}$ flow of $\mathrm{N}_{2}$. A nominal heating rate of $20^{\circ} \mathrm{C} / \mathrm{min}$ was used, and continuous records of sample temperature, sample weight, and heat flow were taken. All measurements were performed in triplicate.

\subsubsection{Equilibrium Water Sorption Isotherms (ESI)}

The hydration behavior of all samples was studied employing the ESI method $[35,36]$. The isothermal sorption curves were determined at room temperature (RT, $\sim 20^{\circ} \mathrm{C}$ ) by placing the samples in sealed desiccators and exposing them to water vapor atmospheres of various relative humidities $(r h)$. The $r h$ of $2\left(\mathrm{P}_{2} \mathrm{O}_{5}\right), 19,33,43,54,64,75,85,95$, and $98 \%$ were achieved with appropriately chosen binary saturated aqueous solutions listed in previous work [37]. The samples were equilibrated for 7 days in each $r h$, and the attainment of equilibrium was determined via the recording of the sample weight $\left(m_{\text {hydr }}\right)$. Measurements were performed simultaneously for three samples of the same type, and results are presented here as averages. A high accuracy Mettler Toledo balance with a sensitivity of $10^{-5} \mathrm{~g}$ was employed for these measurements. The weights of samples after 
equilibration over $\mathrm{P}_{2} \mathrm{O}_{5}$ were considered as weights in dry state $\left(m_{d r y}\right)$. The hydration (water content) was calculated on dry basis, $h_{d}$, through Equation (1).

$$
h_{d}=\frac{m_{\text {water }}}{m_{d r y}}=\frac{m_{h y d r}-m_{d r y}}{m_{d r y}}
$$

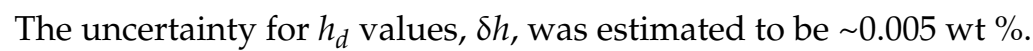

\subsubsection{In Vitro Dissolution Studies}

For the in vitro release studies, a DISTEK Dissolution Apparatus Evolution 4300, equipped with an autosampler using the paddle method (USP II method), was used. A sponge corresponding to $500 \mathrm{mg}$ of each formulation was placed in each dissolution vessel, in an appropriate transdermal patch holder, with its application side up. The test was performed at $37 \pm 1{ }^{\circ} \mathrm{C}$ with a rotation speed of $100 \mathrm{rpm}$. The dissolution medium was $1000 \mathrm{~mL}$ of a phosphate buffered saline (PBS), $\mathrm{pH}=7.2$. Two (2) $\mathrm{mL}$ of aqueous solution were withdrawn from the release media and analyzed for CHL content with the aid of a Shimadzu HPLC system. The column used was a CNW Technologies Athena C18, 120 A, $5 \mu \mathrm{m}, 250 \mathrm{~mm} \times 4.6 \mathrm{~mm}$ at a column temperature of $25^{\circ} \mathrm{C}$. The mobile phase consisted of ACN $/ \mathrm{H}_{2} \mathrm{O}$ (acidified with phosphoric acid at final $\mathrm{pH}=5$ ) $40 / 60 \mathrm{v} / \mathrm{v}$, at a flow rate of $1.0 \mathrm{~mL} / \mathrm{min}$ ). A concentration determination was performed using an HPLC-UV apparatus at $278 \mathrm{~nm}$ and was based on a previously created calibration curve. The injection volume was $20 \mu \mathrm{L}$. The calibration curve was created by diluting a stock methanol solution of $40 \mathrm{ppm}$ CHL to concentrations of $0.01,0.05,0.1,0.5,1.0,5.0,10.0$, and $20 \mathrm{ppm}$ using mobile phase.

\section{Results and Discussion}

\subsection{Preparation and Characterization of PVA/CNF Sponges}

In this study, physical crosslinking was selected to prepare PVA sponges reinforced with CNF. PVA has a pendant hydroxyl group per repeating unit and is, thus, expected to form intermolecular bonds with CNFs, resulting in increased mechanical properties. In brief, aqueous dispersions of CNF were added to a $3 \mathrm{wt} \%$ PVA solution. The dispersions were homogenized, freezed at $-4^{\circ} \mathrm{C}$, and further lyophilized at $-60^{\circ} \mathrm{C}(24 \mathrm{~h})$. The resulting preparations were white in color with a foam-like structure, which will be further discussed.

Fourier transform infrared spectroscopy (FTIR) was used to confirm the incorporation of CNFs in the PVA matrix [38]. The FTIR spectra of the PVA/CNF sponges are presented in Figure 1. The large absorption band observed between 3550 and $3200 \mathrm{~cm}^{-1}$ is attributed to the stretching vibration of the $\mathrm{O}-\mathrm{H}$ groups in $\mathrm{PVA}$, that are subjected to intramolecular (between PVA chains) and intermolecular (between PVA and CNF) hydrogen-bonding. The absorption peak observed around $2900 \mathrm{~cm}^{-1}$ is attributed to the stretching vibration of $\mathrm{C}-\mathrm{H}$ bonds of alkyl groups, and the peak between $1750-1735 \mathrm{~cm}^{-1}$ is due to the stretching vibration of the carbonyl group of the residual acetate groups that have not been hydrolyzed [14]. For CNF, the strong absorption bands at $3451 \mathrm{~cm}^{-1}$ and around $2899 \mathrm{~cm}^{-1}$ are credited to the $\mathrm{O}-\mathrm{H}$ and $\mathrm{C}-\mathrm{H}$ stretching vibrations, respectively. The peak at $1644 \mathrm{~cm}^{-1}$ was reported as the $\mathrm{O}-\mathrm{H}$ vibration of absorbed water. The large absorption band from 1000 to $1160 \mathrm{~cm}^{-1}$ encompasses the "ring breathing" (asymmetric $\mathrm{C}-\mathrm{C}$ vibrations) and $\mathrm{C}-\mathrm{O}-\mathrm{C}$ vibrations of the pyranose ring, as well as the $\mathrm{C}-\mathrm{OH}$ vibration of primary and secondary alcohol groups [39,40]. This characteristic absorption band is also observed in the PVA/CNF composites, overlapping with the band attributed to $\mathrm{C}-\mathrm{OH}$ vibrations of PVA, confirming the successful incorporation of CNFs in PVA. The slight shift of the $\mathrm{O}-\mathrm{H}$ absorption band in PVA/CNF composites, compared to CNF or neat PVA, indicates intermolecular H-bonding interactions between CNFs and PVA [41]. 


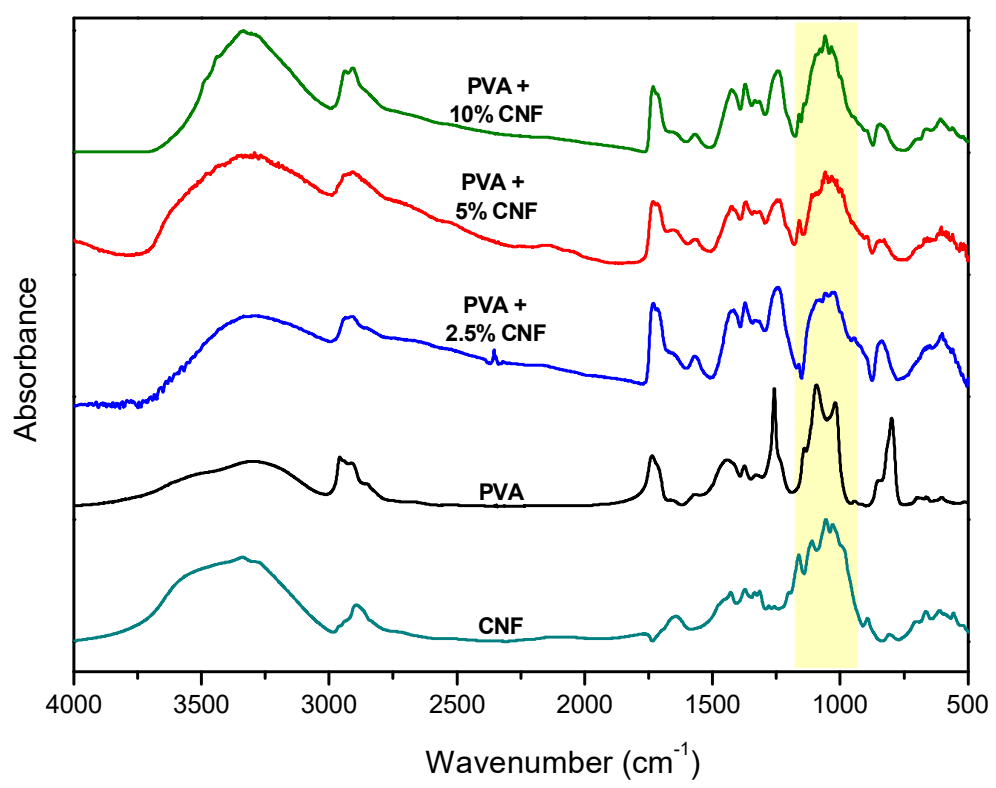

Figure 1. FTIR spectra of PVA/CNF sponges, compared with neat PVA and neat CNF.

Figure 2 presents the $\mathrm{X}$-ray powder diffraction profiles of PVA and CNF compared to PVA/CNF composites. PVA exhibits a characteristic single peak (110 plane) [42]. Five peaks can be clearly observed in the XRD pattern of CNFs at approximate $2 \theta$ values of $14.8^{\circ}$ (101 plane), $16.3^{\circ}$ (101 plane), $20.2^{\circ}$ (021 plane), 22.3 (002 plane), and $34.4^{\circ}$ (040 plane). This pattern is associated with the crystalline structure of cellulose type I $[43,44]$. The crystallinity of CNFs is clearly retained in the composites with 2.5 and $5 \mathrm{wt} \% \mathrm{CNFs}$, while a decrease in crystallinity is observed of the composite containing $10 \mathrm{wt} \% \mathrm{CNF}$. In the literature, the decrease in crystallinity with increasing nanocellulose content is attributed to the random dispersion of CNCs, which impedes the formation of CNC crystal lattices [45].

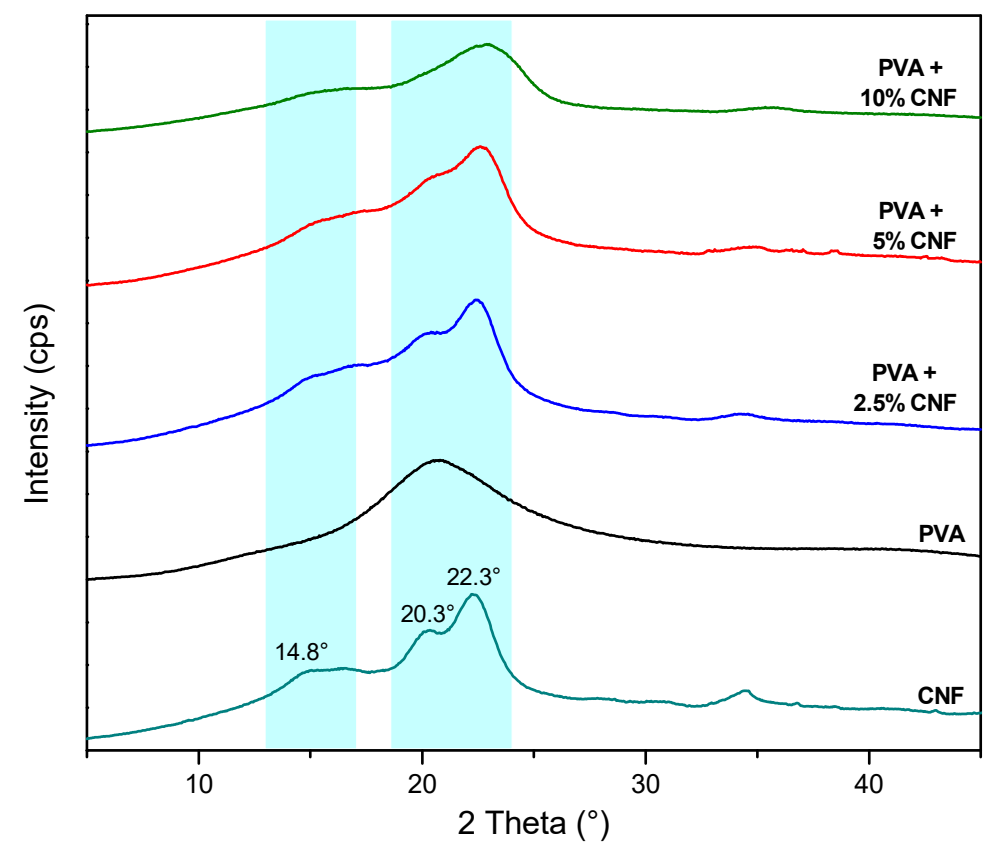

Figure 2. XRD of prepared poly(vinyl alcohol) (PVA)/cellulose nanofibril (CNF) sponges, compared with neat PVA and CNF. 
Figure 3 shows the compressive stress for the composites for a $70 \%$ compressive strain. Generally, with increasing compressive strain, the compressive stress-strain curves for porous foam materials show an initial linear region, followed by a plateau-like state, corresponding to the buckling of the walls of the foam cells, and, finally, an important increase in the stress when the foam walls begin to crush $[46,47]$. As observed in Figure 3 , the compressive strength of the PVA/CNF composites steadily increases as the nanocellulose percentage is augmented. PVA/CNF $10 \mathrm{wt} \%$ exhibited the higher compressive strength among the samples with a maximum stress value of approximately $10 \mathrm{MPa}$. This increase is attributed to the addition of nanocellulose fibers, which confer good, considering their high porosity, mechanical properties to the composites. As a result, the composite with $10 \% \mathrm{CNF}$ was selected for the encapsulation of chloramphenicol (CHL). Additionally, the hydration of the PVA/CNF composites was studied, giving interesting insights into the structure of the composites. These results will be further discussed in Section 3.2.

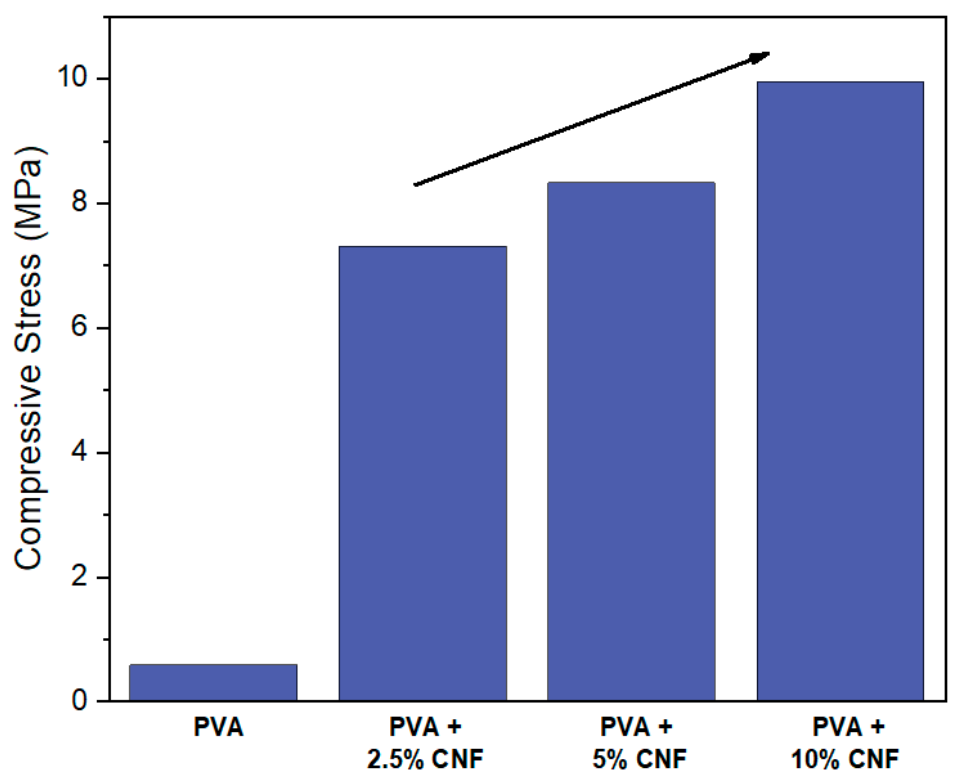

Figure 3. Compressive stress of prepared PVA/CNF sponges.

\subsection{Chloramphenicol Loaded PVA/CNF Sponges}

Chloramphenicol (Scheme 1) is a broad-spectrum antibiotic, generally stable under ordinary storage conditions. However, despite bearing two hydroxyl groups, CHL is characterized by a low solubility in water, which limits its bioavailability. Hydrophilic excipients or oily vehicles are generally used for the preparation of pharmaceutical formulations containing CHL [48]. The aim of the current study was to explore the possibility of incorporating CHL in PVA/CNF composite polymeric matrices, which are appropriate for wound dressings, in order to increase its therapeutic efficacy in topical treatments. The PVA/CNF composites containing $10 \%$ of CNF were selected for the incorporation of CHL after showing better mechanical properties (Figure 3), while no significant changes were observed in their hydration properties (as will be further detailed). The PVA/CNF sponges were loaded with three different CHL ratios: 10, 20, and 30 wt \% (Figure 4).

Regarding the FTIR spectra of pure chloramphenicol (Figure 5), IR absorption peaks for $\mathrm{O}-\mathrm{H}$ and $\mathrm{N}-\mathrm{H}$ stretching vibrations are noted at 3500 and $3235 \mathrm{~cm}^{-1}$, respectively, and aromatic $\mathrm{C}-\mathrm{H}$ stretching vibrations are observed at $3074 \mathrm{~cm}^{-1}$. The peak of the carbonyl group $(\mathrm{C}=\mathrm{O})$ stretching vibrations is recorded at $1683 \mathrm{~cm}^{-1}$. Additionally, $\mathrm{NO}_{2}$ stretching peaks are observable at $1550-1500 \mathrm{~cm}^{-1}$. Most of the characteristic absorption peaks of CHL can be found in the CHL loaded PVA/CNF sponges, especially in the most concentrated one, confirming the successful incorporation of $\mathrm{CHL}$. We can notably mention the $\mathrm{C}=\mathrm{O}$ stretching vibration at $1683 \mathrm{~cm}^{-1}$. 

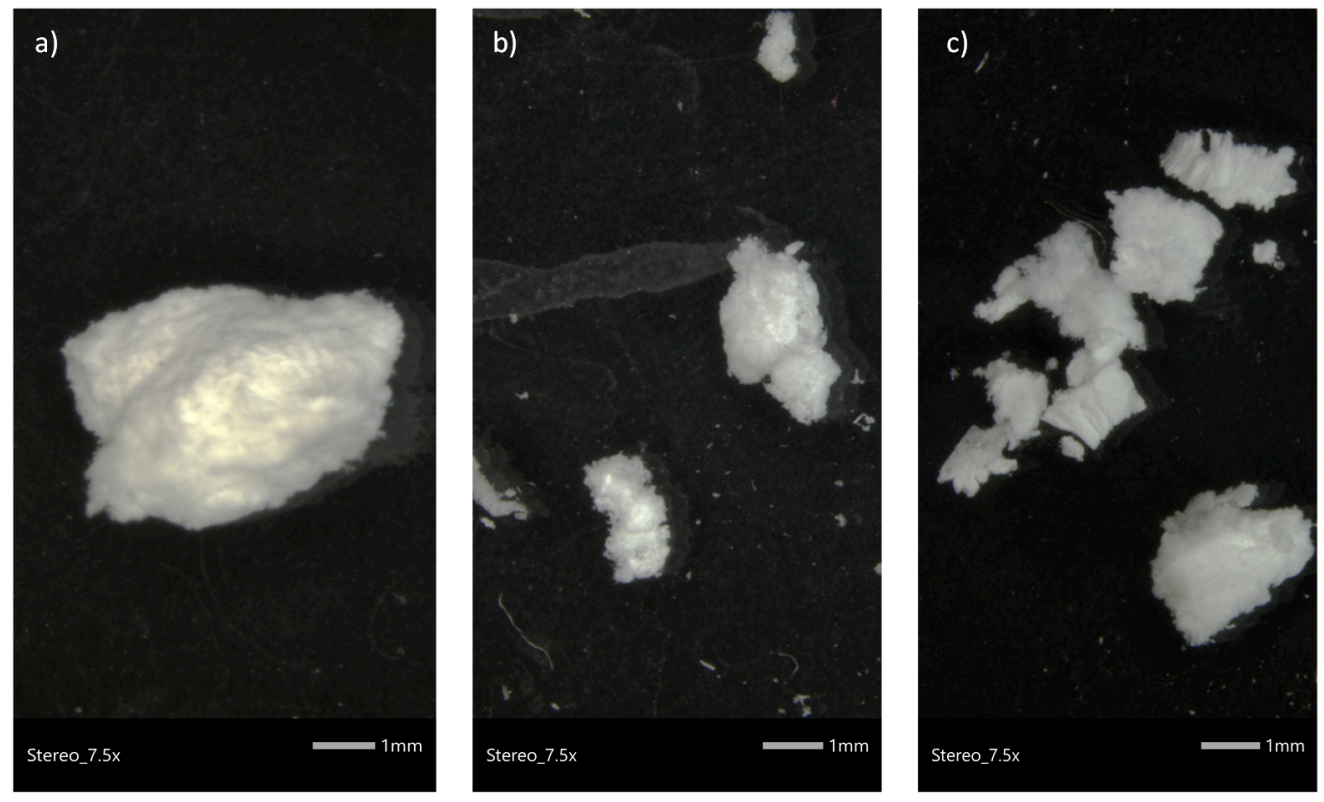

Figure 4. Stereo microscope images of the drug loaded sponges: (a) PVA/CNF/CHL $10 \mathrm{wt} \%$, (b) PVA/CNF/CHL $20 \mathrm{wt} \%$, and (c) PVA/CNF/CHL $30 \mathrm{wt} \%$.

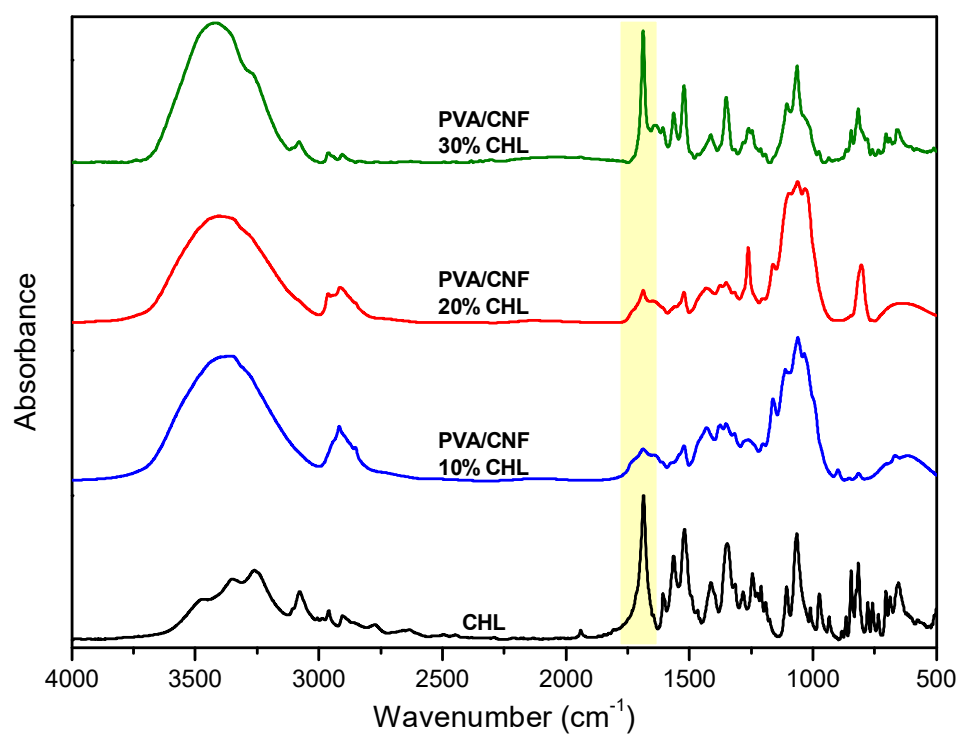

Figure 5. Infrared spectra of the prepared poly(vinyl alcohol) (PVA)/cellulose nanofibrils $(\mathrm{CNF}) /$ chloramphenicol (CHL) sponges with different $\mathrm{CHL}$ ratios.

XRD was used to identify the physical state of the drug in the PVA/CNF composites after drug loading. In the case of the pure $\mathrm{CHL}$, the diffractogram (Figure 6) showed that the active pharmaceutical ingredient (API) is highly crystalline, with clear XRD peaks appearing at $2 \theta=7.8^{\circ}, 10.7^{\circ}, 12.8^{\circ}, 15.5^{\circ}, 18.8^{\circ}, 19.7^{\circ}, 20.1^{\circ}, 20.5^{\circ}, 25.7^{\circ}, 30.5^{\circ}$, and $31.4^{\circ}$. In the case of CHL loaded blends, amorphous API dispersions are observed at up to $20 \%$ $w / w$ of drug loading, while crystalline peaks of CHL are observable in the diffractogram of the sponge containing $30 \%$ of $\mathrm{CHL}$, probably due to some partial recrystallization of CHL or some superficial deposition $[3,49]$. 


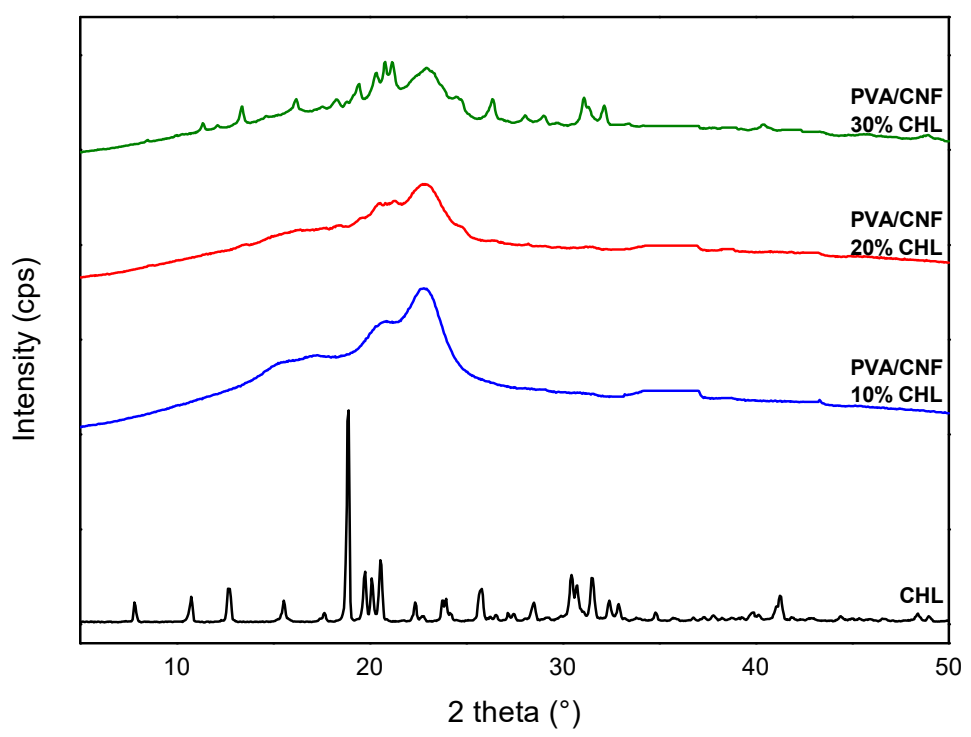

Figure 6. X-ray diffractograms of the prepared poly(vinyl alcohol) (PVA)/cellulose nanofibrils $(\mathrm{CNF})$ / chloramphenicol (CHL) sponges with different CHL ratios, compared with CHL.

The hydration behaviors of all the prepared composites, as well as the impact of the presence of CNF on the composites, were also investigated. The results by ESI at RT have been included in Table 1 and are shown comparatively in Figure 7.

Table 1. Hydrations on dry sample basis, for the samples as received at ambient humidity, $h_{d, a m b}$, and subjected to various relative humidities, $h_{d, r h i} \cdot(i=2-98 \%)$.

\begin{tabular}{|c|c|c|c|c|c|c|c|c|c|c|c|c|}
\hline No & Sample & $\begin{array}{c}h_{\mathrm{d}, \mathrm{amb}} \\
(\mathrm{wt})\end{array}$ & $\begin{array}{c}h_{\mathrm{d}, \mathrm{rh} 2} \\
(\mathrm{wt})\end{array}$ & $\begin{array}{c}h_{\mathrm{d}, \mathrm{rh19}} \\
(\mathrm{wt})\end{array}$ & $\begin{array}{c}h_{\mathrm{d}, \mathrm{rh} 33} \\
(\mathrm{wt})\end{array}$ & $\begin{array}{c}h_{\mathrm{d}, \mathrm{rh} 39} \\
(\mathrm{wt})\end{array}$ & $\begin{array}{c}h_{\mathrm{d}, \mathrm{rh} 54} \\
(\mathrm{wt})\end{array}$ & $\begin{array}{c}h_{\mathrm{d}, \mathrm{rh} 64} \\
(\mathrm{wt})\end{array}$ & $\begin{array}{c}h_{\mathrm{d}, \mathrm{rh} 75} \\
(\mathrm{wt})\end{array}$ & $\begin{array}{c}h_{\mathrm{d}, \mathrm{rh} 85} \\
(\mathbf{w t})\end{array}$ & $\begin{array}{c}h_{\mathrm{d}, \mathrm{rh} 95} \\
(\mathrm{wt})\end{array}$ & $\begin{array}{c}h_{\mathrm{d}, \mathrm{rh} 98} \\
(\mathrm{wt})\end{array}$ \\
\hline 1 & $\mathrm{PVA} / \mathrm{H}_{2} \mathrm{O} 0 \% \mathrm{CNF}$ & 0.05 & 0 & 0.03 & 0.05 & 0.06 & 0.09 & 0.11 & 0.16 & 0.23 & 0.40 & 0.59 \\
\hline 2 & $\mathrm{PVA} / \mathrm{H}_{2} \mathrm{O} 2.5 \% \mathrm{CNF}$ & 0.05 & 0 & 0.03 & 0.05 & 0.06 & 0.08 & 0.09 & 0.12 & 0.17 & 0.29 & 0.44 \\
\hline 3 & $\mathrm{PVA} / \mathrm{H}_{2} \mathrm{O} 5 \% \mathrm{CNF}$ & 0.05 & 0 & 0.03 & 0.05 & 0.06 & 0.08 & 0.10 & 0.12 & 0.18 & 0.30 & 0.45 \\
\hline 4 & $\mathrm{PVA} / \mathrm{H}_{2} \mathrm{O} 10 \% \mathrm{CNF}$ & 0.05 & 0 & 0.04 & 0.05 & 0.06 & 0.08 & 0.10 & 0.12 & 0.17 & 0.26 & 0.37 \\
\hline 5 & PVA 10\% CNF + Chloro 10\% & 0.04 & 0 & 0.02 & 0.04 & 0.05 & 0.06 & 0.08 & 0.10 & 0.14 & 0.22 & 0.31 \\
\hline 6 & PVA $10 \%$ CNF + Chloro $20 \%$ & 0.04 & 0 & 0.03 & 0.04 & 0.05 & 0.07 & 0.08 & 0.10 & 0.14 & 0.22 & 0.31 \\
\hline 7 & PVA $10 \%$ CNF + Chloro 30\% & 0.03 & 0 & 0.03 & 0.03 & 0.04 & 0.05 & 0.06 & 0.08 & 0.11 & 0.18 & 0.25 \\
\hline
\end{tabular}
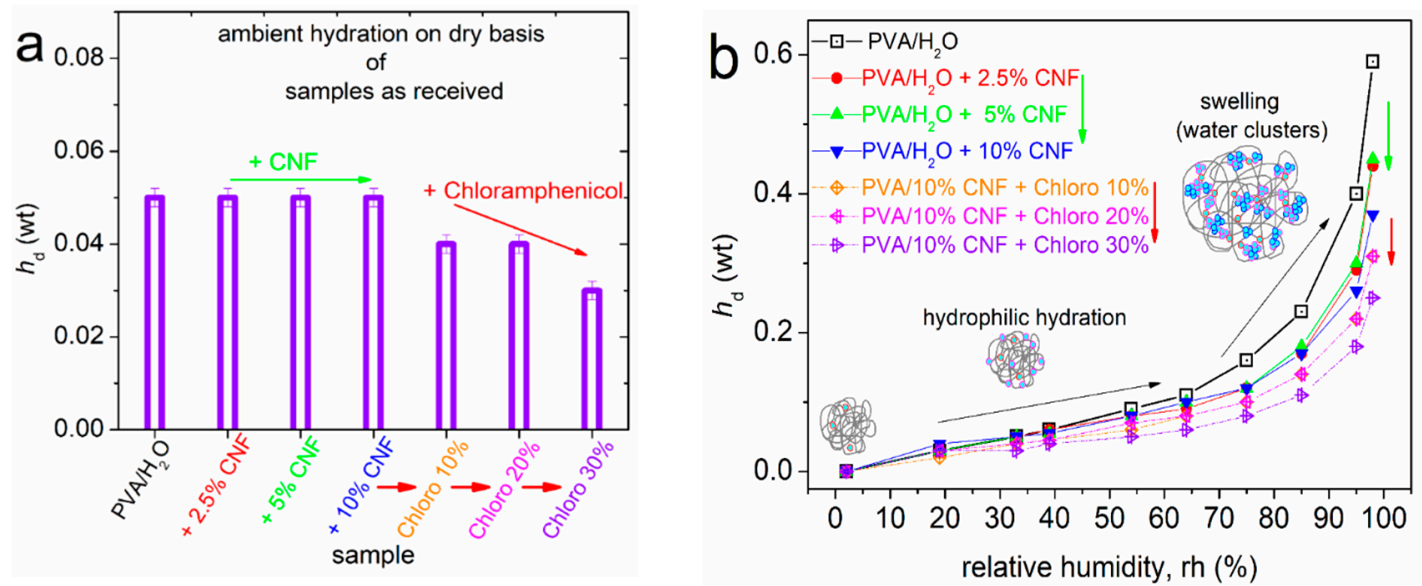

Figure 7. (a) The ambient hydration on dry basis for all samples investigated. The added arrows mark the effects imposed by the CNF content, moreover, by the chloramphenicol amount. (b) Raw data for hydration, $h_{d}$, against relative humidity during the ESI measurements at RT. The inset schemes are used to visually explain the progressive hydration stages. 
We may, firstly, comment on the situation of the samples as received. In Figure 7a, the ambient $h_{d}$ is shown to equal $0.05 \mathrm{wt}$ for neat PVA, which is considered a hydrophilic material, being unchanged in the presence of CNF, independently from the CNF content, and tending to diminish at the addition of chloramphenicol from 0.04 to $0.03 \mathrm{wt}$. Figure $7 \mathrm{~b}$ shows the results for $h_{d}$ over the $r h$ range from $2 \%$ to $98 \%$. The maximum water uptake of PVA is $\sim 0.59 \mathrm{wt}$; then, it drops, with the addition of CNF, down to $0.37 \mathrm{wt}$ and, furthermore, in the presence of the drug, down to $0.25 \mathrm{wt}$.

Qualitatively, the samples exhibit sigmoidal-like $h_{\mathrm{d}}(r h)$ trends, within which, for the low and intermediate $r h(20-65 \%)$, the data correspond to the hydrophilic hydration, namely, the engagement of the polymer's as well as the CNF's hydrophilic sites by water molecules (1st and 2 nd hydration levels). For, $r h \geq 70 \%$, the recorded changes from a linearlike behavior to a strong water uptake are mainly rationalized in terms of the formation of water clusters and, usually, are accompanied by a swelling of the sample $[35,36,50]$. The situation is visually described by the added schemes in Figure $7 \mathrm{~b}$.

Thus, from Figure 7, we may conclude that the presence of chloramphenicol precludes both the hydrophilic hydration and swelling. In fact, this result could indicate that chloramphenicol interacts with PVA, possibly also with CNF, and moderately suppresses the number of the hydrophilic sites.

The results on the high $r h$ (swelling) can be discussed from another point of view. A possible scenario that may rationalize these findings includes the formation of a 'hard' CNF network interpenetrating between PVA chains through the sample volume, limiting the swelling of PVA. Similar examples where the addition of cellulose nanocrystals in hydrophilic polymers (sodium alginate, chitosan) improves their water sensitivity have been reported ([51] and references therein). This could justify the improved mechanical properties of the PVA/CNF composites, compared to neat PVA sponges. Then, the addition of the drug, which is hydrophobic and also 'harder' than the PVA/CNF phase, introduces, on the one hand, a severe reduction in the hydrophilic sites fraction and, on the other hand, an additional difficulty to swelling of the composite system ([50] and references therein). The results obtained by the compression tests (vide supra) provide support, although indirectly, to the abovementioned scenario.

The thermal properties of neat PVA, as well as PVA reinforced with nanocellulose composites and loaded with CHL, are presented in Figure 8. Different states of water exist inside the polymeric matrix of PVA, i.e., absorbed water molecules (weak bonds), which prefer to be on the internal or external surface without causing any interactions with the matrix, and water molecules strongly bound to the hydroxyl groups. On one hand, the thermogravimetric curve of pure PVA exhibits two stages of weight loss. The first stage $\left(260\right.$ to $410^{\circ} \mathrm{C}$ ) is attributed to the loss of water bound to the polymer matrix, and exhibits a maximum mass loss rate at $335{ }^{\circ} \mathrm{C}$. In the second stage (up to $510{ }^{\circ} \mathrm{C}$ ), degradation of PVA, associated with the decomposition and carbonization of the polymer, occurs [52]. On the other hand, $\mathrm{CHL}$ decomposes in roughly three stages: 200-300 ${ }^{\circ} \mathrm{C}$, 300-500 ${ }^{\circ} \mathrm{C}$, and 500-700 ${ }^{\circ} \mathrm{C}[53,54]$. PVA/CNF/CHL composites exhibit a complicated thermal degradation profile, with an earlier onset of degradation compared to PVA. The reduction in thermal stability can be attributed to the incorporation of CNF and CHL, which both have a lower thermal stability compared to neat PVA [42].

SEM was used in order to examine the morphology of the prepared sponges. As shown in Figure 9, a porous structure was formed in all sponges, with pores having sizes of about $10 \mu \mathrm{m}$. Materials loaded with CHL were examined before (Figure 9) and after dissolution (vide infra). For the $10 \mathrm{wt} \% \mathrm{CHL}$ formulation, a smooth surface was observed, indicating that CHL was incorporated into the inner structure of the PVA/CNF sponge. As the content of CHL increased, microparticles of about $300 \mathrm{~nm}$ are also observed on the pore surface, not as deposits but as part of the networks. 


\subsection{Chloramphenicol Release}

\subsubsection{In Vitro Release}

The release of chloramphenicol from the PVA/CNF foams was studied. Drug loading (\%) values are presented in Table 2 . It can be observed that drug loading was increased with increasing amounts of CHL while the opposite was observed for entrapment efficiency. For the sponge containing $10 \mathrm{wt} \% \mathrm{CHL}$, the total amount of the drug was found to be trapped in the sponge. The formulation containing $30 \mathrm{wt} \%$ of $\mathrm{CHL}$ showed, proportionally, the lowest drug loading; the remaining amount of drug not encapsulated, about $4 \%$, is probably deposited on the surface of the formulation. This is in accordance with the XRD results that exhibited an increased crystallinity for the sample containing $30 \mathrm{wt} \% \mathrm{CHL}$. However, even after this small differentiation from the theoretical amount, the CHL loading is rather high.

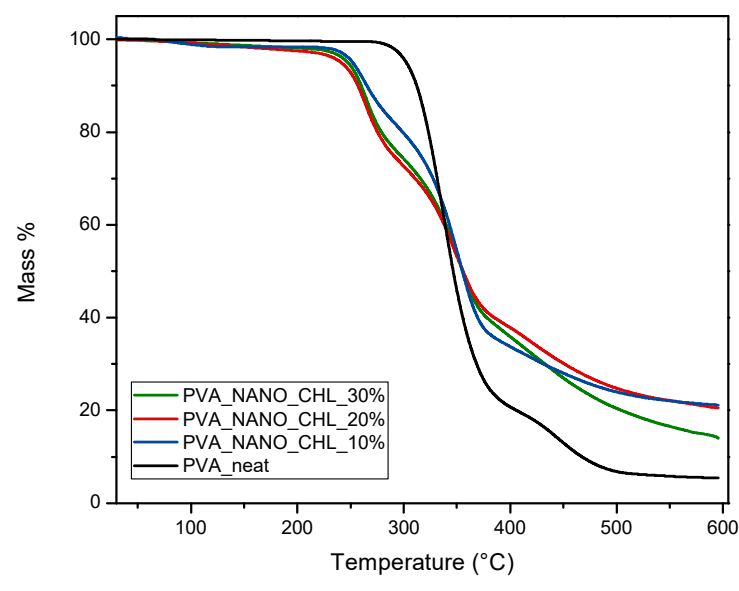

(a)

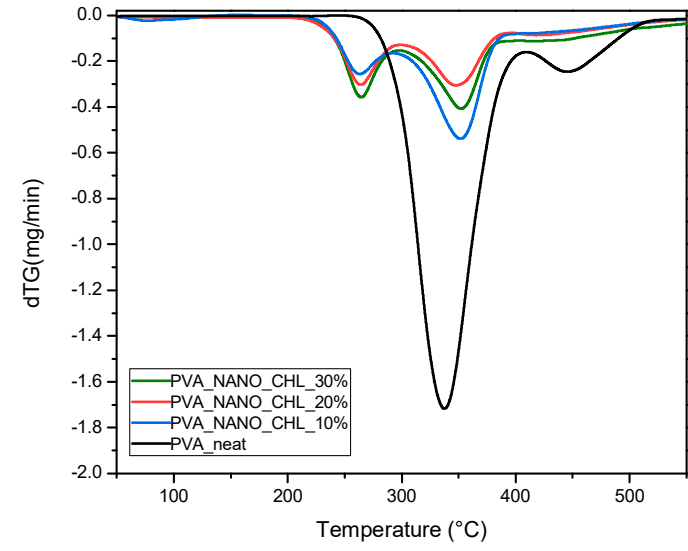

(b)

Figure 8. (a) Thermogravimetric analysis of PVA and PVA/CNF/CHL composites. (b) dTG analysis of PVA and $\mathrm{PVA} / \mathrm{CNF} / \mathrm{CHL}$ composites.
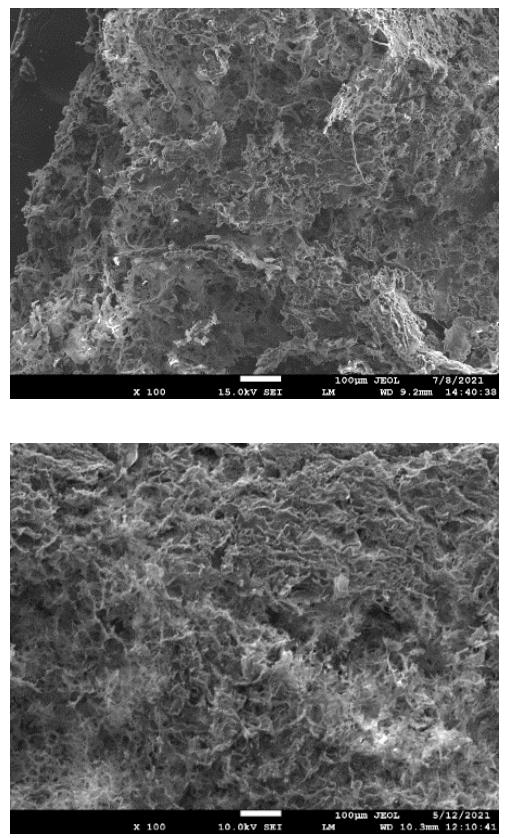

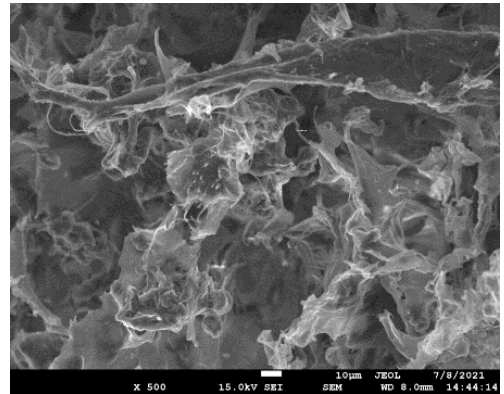

No CHL

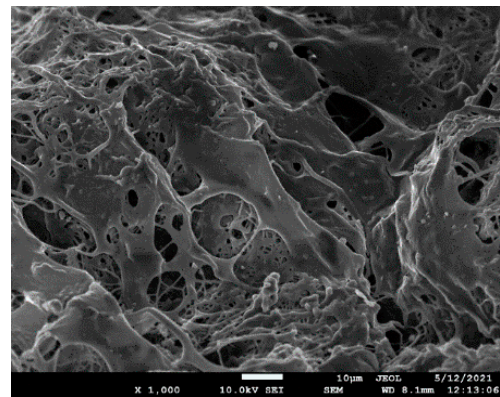

$10 \mathrm{wt} \% \mathrm{CHL}$

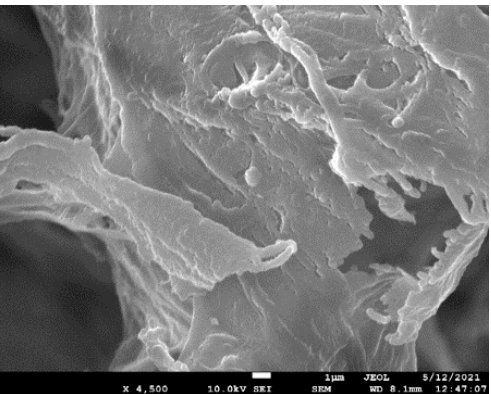

Figure 9. Cont. 

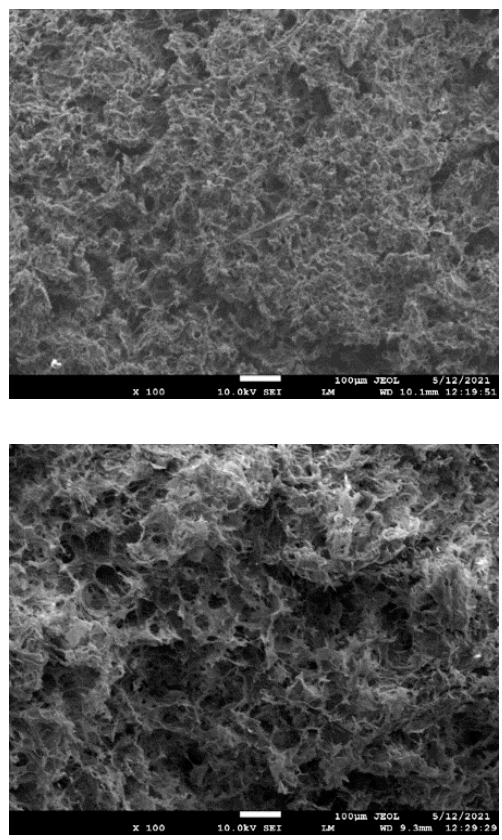

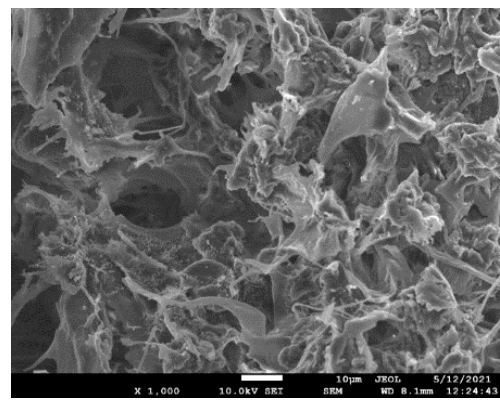

20 wt $\%$ CHL

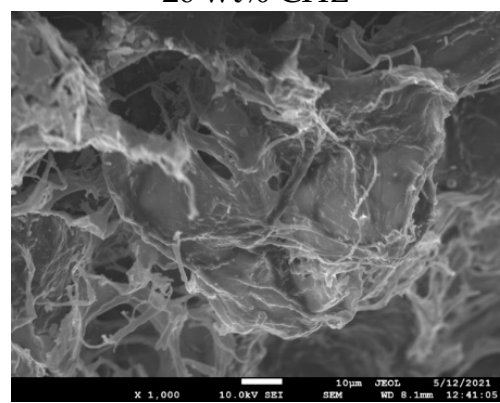

30 wt $\%$ CHL
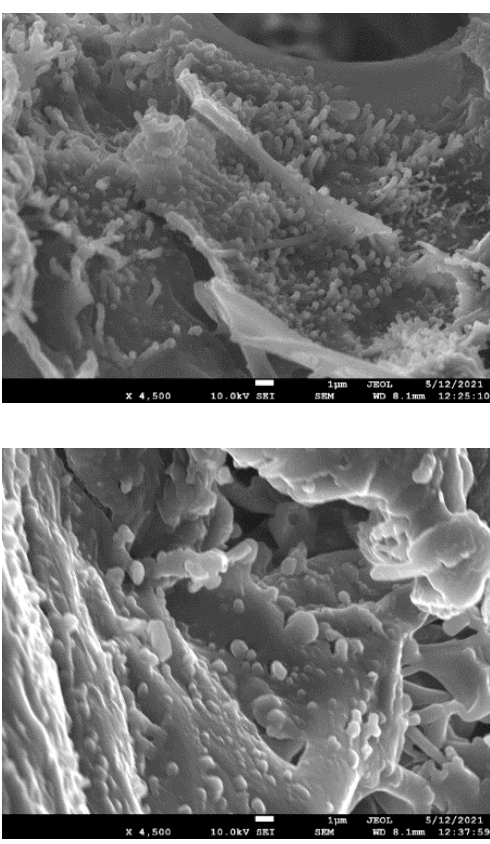

Figure 9. SEM micrographs of and poly(vinyl alcohol) (PVA)/cellulose nanofibrils (CNF) (10 wt \%) sponges with and without chloramphenicol (CHL).

Table 2. Drug-loading and entrapment efficiency for the chloramphenicol loaded sponges.

\begin{tabular}{ccc}
\hline Sample & Drug Loading (\%) & Entrapment Efficiency (\%) \\
\hline PVA /10\% CNF + CHL 10 wt \% & $9.81 \pm 0.31$ & $98.10 \pm 1.09$ \\
PVA /10\% CNF + CHL 20 wt \% & $18.76 \pm 0.94$ & $93.80 \pm 1.84$ \\
PVA /10\% CNF + CHL 30 wt \% & $26.81 \pm 1.67$ & $89.37 \pm 2.03$ \\
\hline
\end{tabular}

A high drug loading of CHL was expected due to the highly porous structure obtained with the PVA/CNF composite containing $10 \mathrm{wt} \%$ CNF (Figure 9). An analogous pore structure was reported by Lu et al., who embedded hydroxypropyl-cellulose fibers in PVA, generating a lot of water-porous area as a result [27]. According to the authors, after freezedrying, porous semi-interpenetrate hydrogels were formed with pores of about $50 \mu \mathrm{m}$ in size. In our study, smaller pores, approximately $10 \mu \mathrm{m}$, were formed independently of the $\mathrm{CHL}$ content, probably owing to the nano sized cellulose used. The porous structure that was created is very convenient for the entrapment of $\mathrm{CHL}$ inside the semi-interpenetrated PVA/CNF network. Finally, it seems that, at $30 \mathrm{wt} \% \mathrm{CHL}$ loading, the total amount of $\mathrm{CHL}$ was not able to be trapped in the inner pore structure, and the excess amount was deposited as crystals on the external surface of the foams, also verifying XRD results.

Figure 10 shows the in vitro release of CHL from the PVA/CHL semi-interpenetrated network compared to pure CHL. The release profile of the sponge containing 10 wt \% CHL showed an initial burst effect, 36.6\% release within the first $30 \mathrm{~min}$, and $50.3 \%$ in $2 \mathrm{~h}$, followed by a controlled release profile, lasting 4 days and achieving a complete release of CHL. For 20 and $30 \mathrm{wt} \%$, an even more abrupt burst release was observed: $46.0 \%$ and $49.5 \%$ respectively, within $30 \mathrm{~min}$. For the $20 \mathrm{wt} \%$ formulation, the release reached $86.7 \%$ in $6 \mathrm{~h}$; a controlled release profile was observed thereafter, reaching $100 \%$ in 2 days. Concerning the $30 \mathrm{wt} \%$ formulation, the release of $\mathrm{CHL}$ reached $83.6 \%$ in $2 \mathrm{~h}$ and $100 \%$ in 1.5 days. Due to its low solubility, CHL showed a maximum release of $80 \%$ as evidenced by the following figure. 


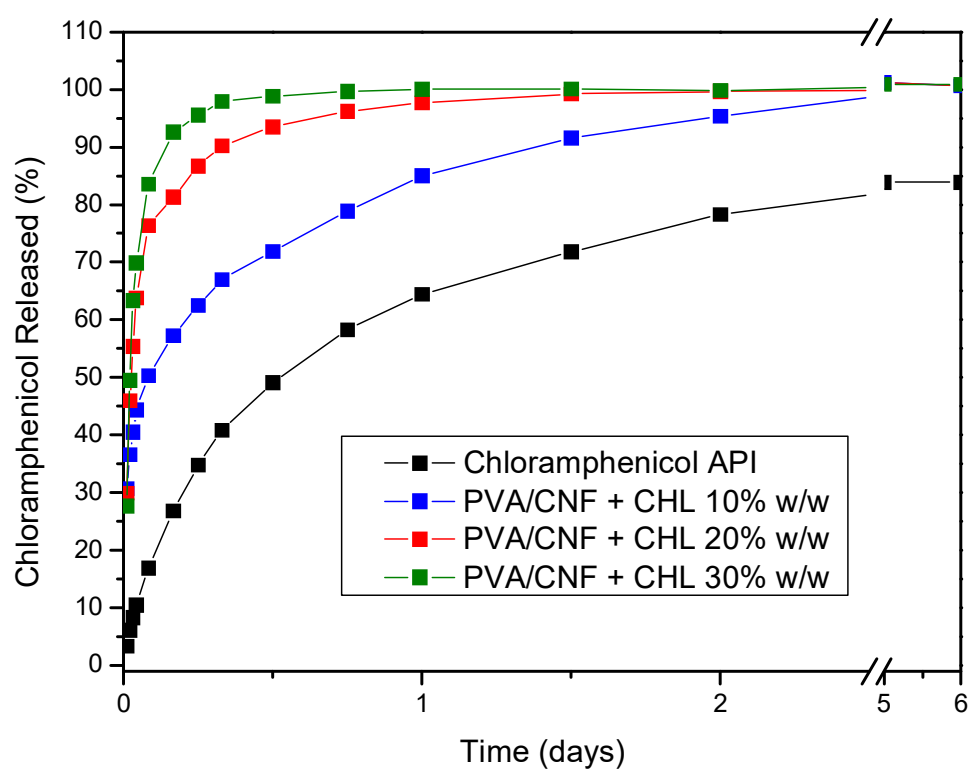

Figure 10. Release profile of poly(vinyl alcohol) (PVA)/cellulose nanofibril (CNF) sponges with $10 \% w / w \mathrm{CNF}$, containing chloramphenicol in 10,20 , and $30 \% w / w$ concentrations, compared to pure CHL.

It is well-known that drug release is controlled by several factors such as polymer swelling, erosion, drug distribution inside the matrix (dispersion state, i.e., amorphous or crystalline), network structure and geometry (i.e., pore size, shape, and distribution), drug solubility and diffusion characteristics, development of API-network interactions, etc. [55]. A biphasic release profile was observed for the composite sponges containing $10 \mathrm{wt} \%$ CHL. The initial burst release can be attributed to surface entrapment of CHL on the outer phase of pore structure and its amorphization [3], and the sustained release to diffusion processes of amorphous CHL trapped inside the semi-interpenetrated foam. The diffusion process appeared to start at about $2 \mathrm{~h}$ and lasted 4 days. As was evidenced by the hydration study, it seems that swelling probably does not play a crucial role in dissolution profile. This is attributable to the $\mathrm{H}$ bonds formed between the hydroxyl groups of PVA and CNF. Strong interactions may reduce water uptake, limiting or even precluding swelling. Analogous hydrogen bond formation was also observed by Forti et al., who studied the reinforcement of hydrophilic polymers, PVA among them, by using fibril cellulose [28]. It was found that strong hydrogen bond formation between hydroxyl groups of PVA and CNF led to products with increased mechanical properties, an observation in accordance with the conclusion of this study. It is believed that increased mechanical properties control the swelling of hydrogels without leading to the deformation of hydrogels.

The results obtained for $20 \mathrm{wt} \%$ CHL content showed that, despite the increased initial burst release, a more progressive release was achieved thereafter, reaching a complete release in 2 days. For the sponges containing 30\% CHL, CHL is almost completely released within $6 \mathrm{~h}$. The initial burst release could be attributed to the high surface area, and the ability of the sponges to encapsulate high quantities of the drug in an amorphous state is something that is also verified by SEM photos (Figures 9 and 11). In addition, the porous structure facilitates the penetration of water, solubilizing the amorphous drug and releasing it into the medium.

SEM photos were also obtained after dissolution, Figure 11. No differences in morphology or pore sizes were observed compared to the initial sponges. However, changes to the inner surface were observed. Indeed, the particles attributed to CHL were not observed anymore. The small particles shown in the photos are probably CNF particles, being more obvious after $\mathrm{CHL}$ dissolution. 

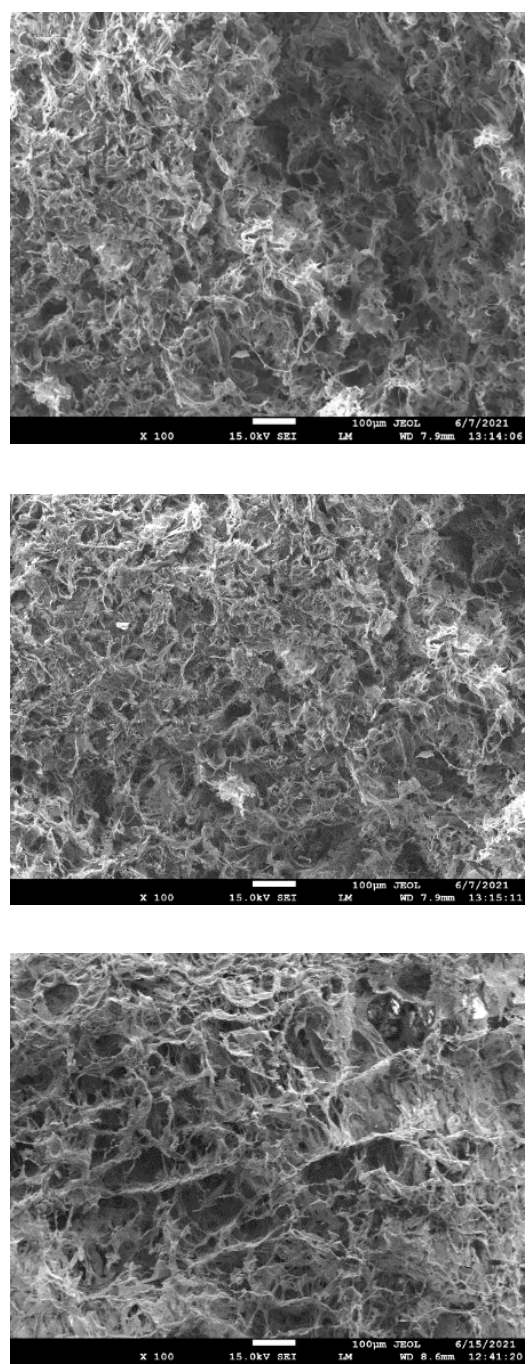

Figure 11. SEM micrographs of prepared poly(vinyl alcohol) (PVA)/cellulose nanofibril (CNF)/chloramphenicol (CHL) sponges after CHL release.

\subsubsection{Modeling of the Release Kinetics}

In this section, an attempt to model the release data is presented. The developed models are essential in quantifying and characterizing the data, to suggest the dominant release mechanisms and, at least in principle, to allow scale up of the data to different release conditions. The data for the neat drug refer to a different mechanism from the data for release from the sponges. The mechanism is a combination of the solid dissociation in liquid and of the mass transfer of the solute from the solid-liquid interface to the bulk of the liquid. The final release fraction is determined by the solubility of the drug in the liquid. Let us call this solubility $C_{e q}$ and $h$ the mass transfer coefficient in the liquid. The two steps of the release process can be described by the following equations:

$$
\begin{gathered}
\frac{d m}{d t}=k A\left(C_{e q}-C_{i}\right)^{n} \\
V \frac{d C}{d t}=h A\left(C_{i}-C\right)
\end{gathered}
$$

where $m$ is the current mass of solid drug, $V$ is the volume of the liquid, $C$ is the bulk liquid concentration of the drug, $t$ is time, $C_{i}$ is the drug concentration in liquid at the solid-liquid interface, $A$ is the solid-liquid interfacial area, and $k, n$ are parameters of the dissociation 
kinetics. It is noted that, in general, the value of $n=1$ is considered [56]. In that case, the above model can be considerably simplified to give (by equating the rate of solid drug decrease to liquid drug increase):

$$
V \frac{d C}{d t}=A\left(\frac{1}{h}+\frac{1}{k}\right)^{-1}\left(C-C_{e q}\right)
$$

The above equation resembles, in form, the well-known Noyes-Whitney equation [57]. However, there is a very important difference. The Noyes-Whitney equation considers that the dissolution depends only on the diffusion step, so the term $(1 / h+1 / k)^{-1}$ is proportional to drug diffusivity in the liquid. Obviously, this is not the case here, where dissociation and convective diffusion contribution are considered. The generalization of the model to arbitrary values of $\mathrm{n}$ is introduced in the present work as a tool to improve the quality of fitting to the experimental data. Considering that the characteristic time of the dissolution process in the present work is of the order of 1 day, and taking into account the agitation performed, it can be reasonably argued that $h>>k$ so the contribution of $h$ in the system $(2,3)$ can be ignored (i.e., $\mathrm{C}_{\mathrm{i}} \approx \mathrm{C}$ ). In this case, the problem is transformed to

$$
V \frac{d C}{d t}=k A\left(C_{e q}-C\right)^{n}
$$

The above equation can be solved analytically to give the following expressions for the percentage cumulative release $R$ :

$$
\begin{gathered}
R=R_{e q}(1-\exp (-A k t / V)) \text { for } n=1 \\
R=R_{e q}\left(1-(1-(1-n) k A t / V)^{1 /(1-n)}\right) \text { for } n \neq 1
\end{gathered}
$$

where $R_{e q}=V C_{e q} / M$, and $M$ is the initial mass of solid drug. The new parameter $K=k A / V$ is introduced for clarity of presentation. At first, the fitting of the experimental data is performed using the expression (6) for $n=1$. The resulting value of $K$ is 1.8 days $^{-1}$. However, the quality of fitting is not as good as it appears in Figure 12. In order to achieve better fitting, the general expression (7) is employed, assuming $n$ also as fitting the parameters. The fitted parameters are $n=1.52$ and $K=2.42$ days $^{-1}$, and the fitting quality is much better. The sum of square deviations between experimental and model data is reduced four-fold. This suggests that the kinetic of drug dissociation is of order 1.5 instead of the usual case of $n=1$.

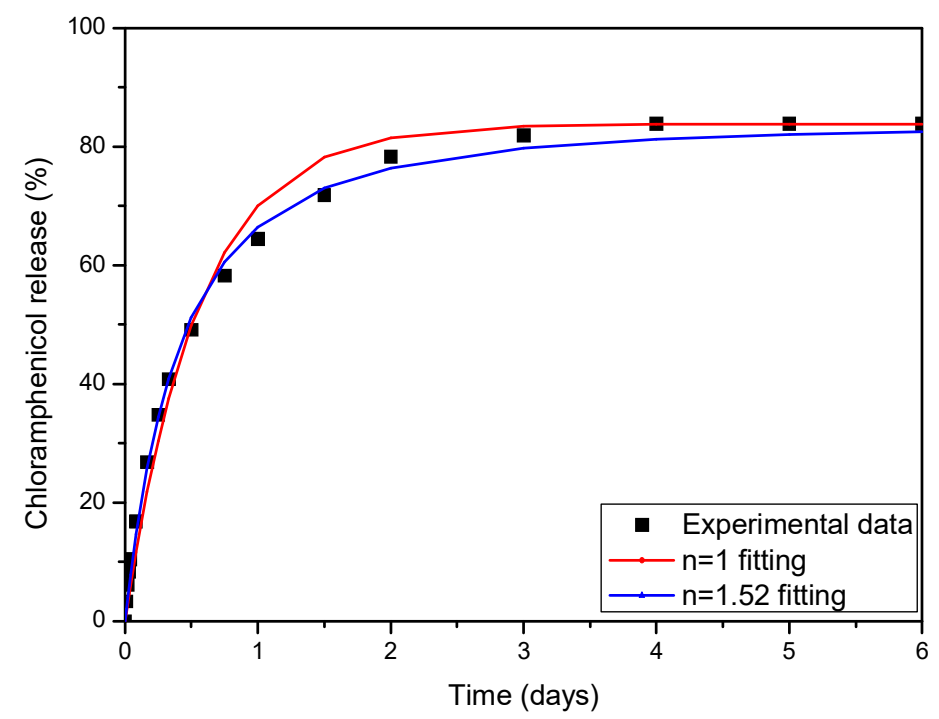

Figure 12. Comparison of experimental neat CHL release data to fitting curves for $n=1$ and $n=1.52$. 
The next step is the attempt of modeling of the release evolution curves from the sponge material. The release from a material undergoing swelling is a very complex process. The water penetrates the sponge, which swells simultaneously. The swelling leads to a decrease in diffusion rate due to the larger distances in swelled material, and to an increase due to the decrease in the porosity and the convection induced by the swelling. There are recent analytical solutions to the release from a material undergoing swelling [58]. However, in practice, it appears that the positive and negative effects of swelling on diffusion are counterbalanced, so a constant (Fickian) diffusion coefficient can be used to describe the experimental release curves [59]. Here, the first attempt is made by considering the solution of the transient diffusion partial differential equation assuming a constant diffusivity. The particular solution has an infinite series form [60] but, for the sake of computation, the first eight terms are employed. The inclusion of so many terms is crucial to capture the initial release burst. The burst of the experimental data is even larger than the one predicted by the theory, so the attempt to fit the model to the data fails. The situation was the same in a previous work for release from sponges [59]. The simplest approach to improve the fitting quality is to consider two populations of drug in the sponge with two different diffusivities. In particular, there is a "fast" population exhibiting release in small time periods and a "slow" population that determines the last period of release. The final equation for the cumulative percentage release $R$ is:

$\frac{R}{100}=\varphi\left(1-\frac{8}{\pi^{2}} \sum_{i=0}^{\infty} \frac{1}{(2 i+1)^{2}} \exp \left(-\frac{D_{1}(2 i+1)^{2} \pi^{2} t}{L_{o}^{2}}\right)\right)+(1-\varphi)\left(1-\frac{8}{\pi^{2}} \sum_{i=0}^{\infty} \frac{1}{(2 i+1)^{2}} \exp \left(-\frac{D_{2}(2 i+1)^{2} \pi^{2} t}{L_{o}^{2}}\right)\right)$

where $\varphi$ is the fraction of the drug population undergoing fast diffusion, and $D_{1}, D_{2}$ are the diffusion coefficients for fast and slow release respectively. As has been stated before, the infinity summation limit is replaced in practice by the number eight. The initial slab thickness is denoted by $L_{0}$. The values of $L_{o}$ for the $10 \%, 20 \%$, and $30 \% w / w$ drug loadings are $1.7,2.3$, and $1.8 \mathrm{~cm}$ respectively.

The relation (8) is employed to fit the experimental release data, with $\varphi, D_{1}$, and $D_{2}$ as fitting parameters. The comparison between fitting results and experimental data appears in Figure 13. The fitting quality is high, and the deviation from the experimental data is comparable to their experimental uncertainty. The value of parameters derived from the fitting procedure is shown in Table 3 below.

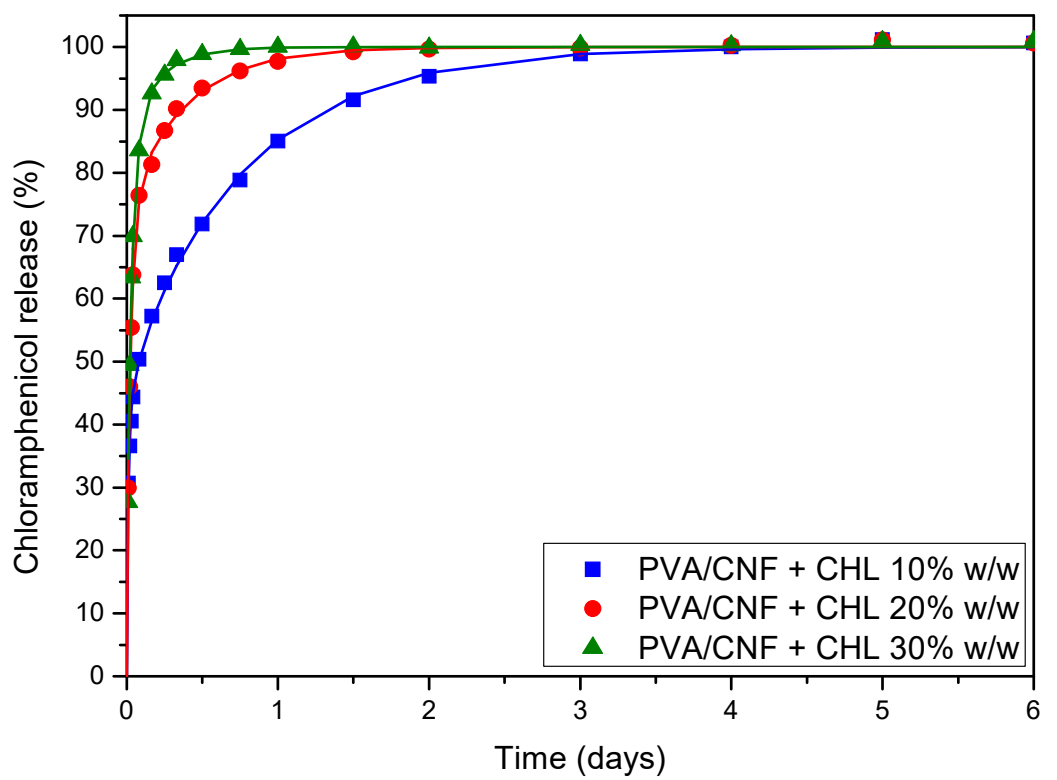

Figure 13. Comparison of experimental release data (symbols) to fitting curves (continuous lines) for the three different loadings of drug. 
Table 3. Parameters obtained by fitting Equation (5) to experimental release data.

\begin{tabular}{lccc}
\hline & $\boldsymbol{\varphi}$ & $D_{\mathbf{1}}\left(\mathrm{m}^{\mathbf{2}} / \mathbf{s}\right)$ & $D_{\mathbf{2}}\left(\mathrm{m}^{\mathbf{2}} / \mathbf{s}\right)$ \\
\hline PVA $/$ CNF + CHL 10 wt $\%$ & 0.35 & $1.17 \times 10^{-7}$ & $1.73 \times 10^{-9}$ \\
PVA/CNF + CHL 20 wt $\%$ & 0.68 & $8.27 \times 10^{-8}$ & $6.48 \times 10^{-9}$ \\
PVA/CNF + CHL 30 wt $\%$ & 0.82 & $4.35 \times 10^{-8}$ & $7.56 \times 10^{-9}$ \\
\hline
\end{tabular}

There are clear trends for the behavior of the parameters $\varphi, D_{1}$, and $D_{2}$ with respect to drug loading. It is obvious that the fraction of the "fast" drug increases as the drug loading increases. In the same manner, $D_{1}$ decreases and $D_{2}$ increases with drug loading increase. One could fit a second-degree polynomial to describe the dependence of each parameter on drug loading, giving a predicting capability to the model. The values of the diffusion coefficients are very surprising. Not only the "fast" diffusivities, but also the "slow" ones, are higher than the molecular diffusivity of the drug in water. This implies that these diffusivities are not real molecular diffusivities, but include contributions of mixing type imposed by convection induced by swelling.

\section{Conclusions}

In the present study, poly(vinyl alcohol) sponges were reinforced with cellulose nanofibrils to reduce water sensitivity and increase the mechanical properties of PVA sponges for wound dressing applications. Indeed, the compressive strength was significantly increased, and hydration studies showed that swelling was limited, probably due to the formation of a harder CNF network, interpenetrating with the PVA chains. Chloramphenicol, a broad-spectrum antibiotic, was further loaded in the sponges, and a sustained release was observed, especially for the sponge containing the lowest amount of CHL. The differences were attributed to the location of drug within the inner porous structure vs. on the external surface. These observations were complemented by SEM photos and in vitro dissolution studies, which reveal a good CHL dispersion and a fast drug release (2 days) for PVA/CNF/CHL composites. All the obtained results indicate that the obtained PVA/CNF/CHL sponges are potentially suitable for wound dressings, and further studies will be implemented to determine their biocompatibility as well as in vitro and in vivo performances.

Author Contributions: Conceptualization, G.Z.P., K.C., and A.K.; formal analysis, E.D.B., N.D.B., C.P., M.K., P.A.K., S.G.N., and A.Z.; writing-original draft preparation, E.D.B., N.D.B., S.G.N., M.K., P.A.K., and A.Z.; writing-review and editing, G.Z.P., S.G.N., K.C., A.K., and A.Z.; supervision, G.Z.P. All authors have read and agreed to the published version of the manuscript.

Funding: This research received no external funding.

Institutional Review Board Statement: Not applicable.

Informed Consent Statement: Not applicable.

Data Availability Statement: The data presented in this study are available on request from the corresponding author.

Conflicts of Interest: The authors declare no conflict of interest.

\section{References}

1. Kus, K.J.B.; Ruiz, E.S. Wound Dressings-A Practical Review. Curr. Dermatol. Rep. 2020, 9, 298-308. [CrossRef]

2. Hawthorne, B.; Simmons, J.K.; Stuart, B.; Tung, R.; Zamierowski, D.S.; Mellott, A.J. Enhancing wound healing dressing development through interdisciplinary collaboration. J. Biomed. Mater. Res. Part B Appl. Biomater. 2021. (early view). [CrossRef]

3. Michailidou, G.; Christodoulou, E.; Nanaki, S.; Barmpalexis, P.; Karavas, E.; Vergkizi-Nikolakaki, S.; Bikiaris, D.N. Superhydrophilic and high strength polymeric foam dressings of modified chitosan blends for topical wound delivery of chloramphenicol. Carbohydr. Polym. 2019, 208, 1-13. [CrossRef]

4. Jiang, L.; Loo, S.C.J. Intelligent Nanoparticle-Based Dressings for Bacterial Wound Infections. ACS Appl. Bio Mater. 2021, 4, 3849-3862. [CrossRef] 
5. Bal-Öztürk, A.; Özkahraman, B.; Özbaş, Z.; Yaşayan, G.; Tamahkar, E.; Alarçin, E. Advancements and future directions in the antibacterial wound dressings-A review. J. Biomed. Mater. Res. Part B Appl. Biomater. 2021, 109, 703-716. [CrossRef]

6. Asadi, N.; Pazoki-Toroudi, H.; Del Bakhshayesh, A.R.; Akbarzadeh, A.; Davaran, S.; Annabi, N. Multifunctional hydrogels for wound healing: Special focus on biomacromolecular based hydrogels. Int. J. Biol. Macromol. 2021, 170, 728-750. [CrossRef]

7. Szczeblinska, J.; Fijalkowski, K.; Kohn, J.; El Fray, M. Antibiotic loaded microspheres as antimicrobial delivery systems for medical applications. Mater. Sci. Eng. C 2017, 77, 69-75. [CrossRef] [PubMed]

8. Terzopoulou, Z.; Michopoulou, A.; Palamidi, A.; Koliakou, E.; Bikiaris, D. Preparation and Evaluation of Collagen-Based Patches as Curcumin Carriers. Polymers 2020, 12, 2393. [CrossRef] [PubMed]

9. Nanaki, S.G.; Andrianidou, S.; Barmpalexis, P.; Christodoulou, E.; Bikiaris, D.N. Leflunomide Loaded Chitosan Nanoparticles for the Preparation of Aliphatic Polyester Based Skin Patches. Polymers 2021, 13, 1539. [CrossRef]

10. Siafaka, P.I.; Zisi, A.P.; Exindari, M.K.; Karantas, I.D.; Bikiaris, D.N. Porous dressings of modified chitosan with poly(2hydroxyethyl acrylate) for topical wound delivery of levofloxacin. Carbohydr. Polym. 2016, 143, 90-99. [CrossRef] [PubMed]

11. Ghalei, S.; Asadi, H.; Ghalei, B. Zein nanoparticle-embedded electrospun PVA nanofibers as wound dressing for topical delivery of anti-inflammatory diclofenac. J. Appl. Polym. Sci. 2018, 135, 46643. [CrossRef]

12. Koumentakou, I.; Terzopoulou, Z.; Michopoulou, A.; Kalafatakis, I.; Theodorakis, K.; Tzetzis, D.; Bikiaris, D. Chitosan dressings containing inorganic additives and levofloxacin as potential wound care products with enhanced hemostatic properties. Int. J. Biol. Macromol. 2020, 162, 693-703. [CrossRef] [PubMed]

13. Balla, E.; Daniilidis, V.; Karlioti, G.; Kalamas, T.; Stefanidou, M.; Bikiaris, N.D.; Vlachopoulos, A.; Koumentakou, I.; Bikiaris, D.N. Poly(lactic Acid): A Versatile Biobased Polymer for the Future with Multifunctional Properties-From Monomer Synthesis, Polymerization Techniques and Molecular Weight Increase to PLA Applications. Polymers 2021, 13, 1822. [CrossRef] [PubMed]

14. Mansur, H.S.; Sadahira, C.M.; Souza, A.N.; Mansur, A.A.P. FTIR spectroscopy characterization of poly(vinyl alcohol) hydrogel with different hydrolysis degree and chemically crosslinked with glutaraldehyde. Mater. Sci. Eng. C 2008, 28, 539-548. [CrossRef]

15. Katopodis, K.; Kapourani, A.; Vardaka, E.; Karagianni, A.; Chorianopoulou, C.; Kontogiannopoulos, K.N.; Bikiaris, D.N.; Kachrimanis, K.; Barmpalexis, P. Partially hydrolyzed polyvinyl alcohol for fusion-based pharmaceutical formulation processes: Evaluation of suitable plasticizers. Int. J. Pharm. 2020, 578, 119121. [CrossRef]

16. Michailidou, G.; Ainali, N.M.; Xanthopoulou, E.; Nanaki, S.; Kostoglou, M.; Koukaras, E.N.; Bikiaris, D.N. Effect of Poly(vinyl alcohol) on Nanoencapsulation of Budesonide in Chitosan Nanoparticles via Ionic Gelation and Its Improved Bioavailability. Polymers 2020, 12, 1101. [CrossRef]

17. Feldman, D. Poly(vinyl alcohol) nanocomposites: Recent contributions to engineering and medicine. AIMS Mater. Sci. 2021, 8, 119-129. [CrossRef]

18. Palamidi, A.; Kapourani, A.; Christodoulou, E.; Klonos, P.A.; Kontogiannopoulos, K.N.; Kyritsis, A.; Bikiaris, D.N.; Barmpalexis, P. Low Molecular Weight Oligomers of Poly(alkylene succinate) Polyesters as Plasticizers in Poly(vinyl alcohol) Based Pharmaceutical Applications. Polymers 2021, 13, 146. [CrossRef]

19. Trucillo, P.; Di Maio, E. Classification and Production of Polymeric Foams among the Systems for Wound Treatment. Polymers 2021, 13, 1608. [CrossRef]

20. Lee, S.-Y.; Mohan, D.J.; Kang, I.-A.; Doh, G.-H.; Lee, S.; Han, S.O. Nanocellulose reinforced PVA composite films: Effects of acid treatment and filler loading. Fibers Polym. 2009, 10,77-82. [CrossRef]

21. Abitbol, T.; Rivkin, A.; Cao, Y.; Nevo, Y.; Abraham, E.; Ben-Shalom, T.; Lapidot, S.; Shoseyov, O. Nanocellulose, a tiny fiber with huge applications. Curr. Opin. Biotechnol. 2016, 39, 76-88. [CrossRef] [PubMed]

22. Seddiqi, H.; Oliaei, E.; Honarkar, H.; Jin, J.; Geonzon, L.C.; Bacabac, R.G.; Klein-Nulend, J. Cellulose and its derivatives: Towards biomedical applications. Cellulose 2021, 28, 1893-1931. [CrossRef]

23. Moritz, S.; Wiegand, C.; Wesarg, F.; Hessler, N.; Müller, F.A.; Kralisch, D.; Hipler, U.-C.; Fischer, D. Active wound dressings based on bacterial nanocellulose as drug delivery system for octenidine. Int. J. Pharm. 2014, 471, 45-55. [CrossRef] [PubMed]

24. Lin, N.; Dufresne, A. Nanocellulose in biomedicine: Current status and future prospect. Eur. Polym. J. 2014, 59, 302-325. [CrossRef]

25. Tong, W.Y.; bin Abdullah, A.Y.K.; binti Rozman, N.A.S.; bin Wahid, M.I.A.; Hossain, M.S.; Ring, L.C.; Lazim, Y.; Tan, W.-N. Antimicrobial wound dressing film utilizing cellulose nanocrystal as drug delivery system for curcumin. Cellulose 2018, 25, 631-638. [CrossRef]

26. Liu, X.; Yang, K.; Chang, M.; Wang, X.; Ren, J. Fabrication of cellulose nanocrystal reinforced nanocomposite hydrogel with self-healing properties. Carbohydr. Polym. 2020, 240, 116289. [CrossRef]

27. Lu, C.; Wang, C.; Zhang, D.; Wang, J.; Yong, Q.; Chu, F. Ultra-strong hydroxypropyl cellulose/polyvinyl alcohol composite hydrogel by combination of triple-network and mechanical training. Int. J. Biol. Macromol. 2021, 184, 200-208. [CrossRef] [PubMed]

28. Forti, E.S.; El Awad Azrak, S.M.; Ng, X.Y.; Cho, W.; Schueneman, G.T.; Moon, R.J.; Fox, D.M.; Youngblood, J.P. Mechanical enhancement of cellulose nanofibril (CNF) films through the addition of water-soluble polymers. Cellulose 2021, 28, $6449-6465$. [CrossRef]

29. Song, S.; Liu, Z.; Abubaker, M.A.; Ding, L.; Zhang, J.; Yang, S.; Fan, Z. Antibacterial polyvinyl alcohol/bacterial cellulose/nanosilver hydrogels that effectively promote wound healing. Mater. Sci. Eng. C 2021, 126, 112171. [CrossRef] 
30. Zimmermann, T.; Pöhler, E.; Schwaller, P. Mechanical and Morphological Properties of Cellulose Fibril Reinforced Nanocomposites. Adv. Eng. Mater. 2005, 7, 1156-1161. [CrossRef]

31. Sabu, T.; Raghvendra, K.M.; Abdullah, M.A. (Eds.) Sustainable Polymer Composites and Nanocomposites; Springer: Cham, Switzerland, 2019; ISBN 978-3-030-05398-7.

32. Todoran, N.; Ciurba, A.; Rédai, E.; Ion, V.; Lazăr, L.; Sipos, E. Limitations when use chloramphenicol-bcyclodextrins complexes in ophtalmic solutions buffered with boric acid/borax system. Acta Med. Marisiensis 2014, 60, 269-274. [CrossRef]

33. Karava, A.; Lazaridou, M.; Nanaki, S.; Michailidou, G.; Christodoulou, E.; Kostoglou, M.; Iatrou, H.; Bikiaris, D.N. Chitosan Derivatives with Mucoadhesive and Antimicrobial Properties for Simultaneous Nanoencapsulation and Extended Ocular Release Formulations of Dexamethasone and Chloramphenicol Drugs. Pharmaceutics 2020, 12, 594. [CrossRef] [PubMed]

34. Rihawy, M.S.; Alzier, A.; Allaf, A.W. Investigation of chloramphenicol release from PVA/CMC/HEA hydrogel using ion beam analysis, UV and FTIR techniques. Appl. Radiat. Isot. 2019, 153, 108806. [CrossRef] [PubMed]

35. Pissis, P.; Kyritsis, A. Hydration studies in polymer hydrogels. J. Polym. Sci. Part B Polym. Phys. 2013, 51, 159-175. [CrossRef]

36. Klonos, P.; Pissis, P.; Kyritsis, A. Effects of Hydration/Dehydration on Interfacial Polymer Fraction and Dynamics in Nanocomposites Based on Metal-Oxides and Physically Adsorbed Polymer. J. Phys. Chem. C 2017, 121, 19428-19441. [CrossRef]

37. Greenspan, L. Humidity fixed points of binary saturated aqueous solutions. J. Res. Natl. Bur. Stand. Sect. A Phys. Chem. 1977, 81A, 89. [CrossRef]

38. Wang, Z.; Zhao, S.; Hong, L.; Huang, J. Preparation and Properties of Silver-Based Cellulose/Polyvinyl Alcohol Antibacterial Materials. J. Inorg. Organomet. Polym. Mater. 2020, 30, 4382-4393. [CrossRef]

39. Garside, P.; Wyeth, P. Identification of Cellulosic Fibres by FTIR Spectroscopy-Thread and Single Fibre Analysis by Attenuated Total Reflectance. Stud. Conserv. 2003, 48, 269-275. [CrossRef]

40. Yang, Y.P.; Zhang, Y.; Lang, Y.X.; Yu, M.H. Structural ATR-IR analysis of cellulose fibers prepared from a NaOH complex aqueous solution. IOP Conf. Ser. Mater. Sci. Eng. 2017, 213, 012039. [CrossRef]

41. Jayaramudu, T.; Ko, H.-U.; Kim, H.C.; Kim, J.W.; Muthoka, R.M.; Kim, J. Electroactive Hydrogels Made with Polyvinyl Alcohol/Cellulose Nanocrystals. Materials 2018, 11, 1615. [CrossRef]

42. Ching, Y.C.; Rahman, A.; Ching, K.Y.; Sukiman, N.L.; Chuah, C.H. Preparation and characterization of polyvinyl alcohol-based composite reinforced with nanocellulose and nanosilica. BioResources 2015, 10, 3364-3377. [CrossRef]

43. Gong, J.; Li, J.; Xu, J.; Xiang, Z.; Mo, L. Research on cellulose nanocrystals produced from cellulose sources with various polymorphs. RSC Adv. 2017, 7, 33486-33493. [CrossRef]

44. Aguayo, M.G.; Fernández Pérez, A.; Reyes, G.; Oviedo, C.; Gacitúa, W.; Gonzalez, R.; Uyarte, O. Isolation and Characterization of Cellulose Nanocrystals from Rejected Fibers Originated in the Kraft Pulping Process. Polymers 2018, 10, 1145. [CrossRef]

45. Bary, E.M.A.; Fekri, A.; Soliman, Y.A.; Harmal, A.N. Novel superabsorbent membranes made of PVA and Ziziphus spina-christi cellulose for agricultural and horticultural applications. New J. Chem. 2017, 41, 9688-9700. [CrossRef]

46. Ashby, M.F.; Medalist, R.F.M. The mechanical properties of cellular solids. Metall. Trans. A 1983, 14, 1755-1769. [CrossRef]

47. Song, T.; Tanpichai, S.; Oksman, K. Cross-linked polyvinyl alcohol (PVA) foams reinforced with cellulose nanocrystals (CNCs). Cellulose 2016, 23, 1925-1938. [CrossRef]

48. Zuorro, A.; Fidaleo, M.; Lavecchia, R. Solubility enhancement and antibacterial activity of chloramphenicol included in modified $\beta$-cyclodextrins. Bull. Korean Chem. Soc. 2010, 31, 3460-3462. [CrossRef]

49. Ainali, N.M.; Xanthopoulou, E.; Michailidou, G.; Zamboulis, A.; Bikiaris, D.N. Microencapsulation of Fluticasone Propionate and Salmeterol Xinafoate in Modified Chitosan Microparticles for Release Optimization. Molecules 2020, 25, 3888. [CrossRef]

50. Stathopoulos, A.; Klonos, P.; Kyritsis, A.; Pissis, P.; Christodoulides, C.; Hernández, J.C.R.; Pradas, M.M.; Ribelles, J.L.G. Water sorption and polymer dynamics in hybrid poly(2-hydroxyethyl-co-ethyl acrylate)/silica hydrogels. Eur. Polym. J. 2010, 46, 101-111. [CrossRef]

51. Abdollahi, M.; Alboofetileh, M.; Behrooz, R.; Rezaei, M.; Miraki, R. Reducing water sensitivity of alginate bio-nanocomposite film using cellulose nanoparticles. Int. J. Biol. Macromol. 2013, 54, 166-173. [CrossRef]

52. Gomaa, M.M.; Hugenschmidt, C.; Dickmann, M.; Abdel-Hady, E.E.; Mohamed, H.F.M.; Abdel-Hamed, M.O. Crosslinked PVA/SSA proton exchange membranes: Correlation between physiochemical properties and free volume determined by positron annihilation spectroscopy. Phys. Chem. Chem. Phys. 2018, 20, 28287-28299. [CrossRef]

53. Frunza, M.; Lisa, G.; Popa, M.I.; Miron, N.D.; Nistor, D.I. Thermogravimetric analysis of layered double hydroxides with chloramphenicol and salicylate in the interlayer space. J. Therm. Anal. Calorim. 2008, 93, 373-379. [CrossRef]

54. Macêdo, R.O.; Aragão, C.F.S.; do Nascimento, T.G.; Macêdo, A.M.C. Application of Thermogravimetry in the Quality Control of Chloramphenicol Tablets. J. Therm. Anal. Calorim. 1999, 56, 1323-1327. [CrossRef]

55. Grassi, M.; Grassi, G. Application of mathematical modeling in sustained release delivery systems. Expert Opin. Drug Deliv. 2014, 11, 1299-1321. [CrossRef]

56. Pappa, C.; Nanaki, S.; Giliopoulos, D.; Triantafyllidis, K.; Kostoglou, M.; Avgeropoulos, A.; Bikiaris, D. Nanostructured Composites of Sodium Montmorillonite Clay and PEO Used in Dissolution Improvement of Aprepitant Drug by Melt Mixing. Appl. Sci. 2018, 8, 786. [CrossRef]

57. Hattori, Y.; Haruna, Y.; Otsuka, M. Dissolution process analysis using model-free Noyes-Whitney integral equation. Colloids Surf. B Biointerfaces 2013, 102, 227-231. [CrossRef] 
58. Setapa, A.; Ahmad, N.; Mohd Mahali, S.; Mohd Amin, M.C. Mathematical Model for Estimating Parameters of Swelling Drug Delivery Devices in a Two-Phase Release. Polymers 2020, 12, 2921. [CrossRef]

59. Lazaridou, M.; Nanaki, S.; Zamboulis, A.; Papoulia, C.; Chrissafis, K.; Klonos, P.A.; Kyritsis, A.; Vergkizi-Nikolakaki, S.; Kostoglou, M.; Bikiaris, D.N. Super absorbent chitosan-based hydrogel sponges as carriers for caspofungin antifungal drug. Int. J. Pharm. 2021, 606, 120925. [CrossRef]

60. Crank, J. The Mathematics of Diffusion, 2nd ed.; Oxford University Press: New York, NY, USA, 1979. 